\title{
Dynamics of PPARs, fatty acid metabolism genes and lipid classes in eggs and early larvae of a teleost
}

\section{Cunha $I^{a^{*}}$, Galante-Oliveira $S^{a \S}$, Rocha $E^{a, b}$, Planas $M^{c}$, Urbatzka $R^{a}$, Castro $\mathbf{L F C}^{\mathbf{a}}$}

${ }^{a}$ Interdisciplinary Centre for Marine and Environmental Research (CIIMAR), CIMAR Associate Laboratory, University of Porto (U.Porto), Portugal

${ }^{b}$ Institute of Biomedical Sciences Abel Salazar (ICBAS), University of Porto (U.Porto), Portugal ${ }^{c}$ Instituto de Investigaciones Marinas (CSIC), Vigo, Spain

${ }^{\S}$ Present address: Department of Biology \& Estudos do Ambiente e do Mar (CESAM), University of Aveiro, Portugal,

"Corresponding author:

Isabel Cunha, Rua dos Bragas 289, 4050-123 Porto, Portugal.

phone: +3512234018 18, fax: +351223390608

E-mail address: isabel.cunha@ciimar.up.pt

\begin{abstract}
Abbreviations: dpf - days post fertilization; FA, fatty acids; FFA, free fatty acids; HUFA, highly unsaturated fatty acids; LPA, Lysophosphatidic acid; MUFA, monounsaturated fatty acids; PL, phospholipids; PPAR - peroxisome proliferator activated receptor; PUFA, polyunsaturated fatty acids; SE, Sterol esters; SL, sterols; SFA, saturated fatty acids; TG, triglycerides; WE, wax esters.
\end{abstract}
Abstract
Dietary long chain polyunsaturated fatty acids (FA) have been recognized of crucial importance in early development of vertebrates, contributing to the impressive morphological and physiological changes both as building blocks and to energy production. The importance of lipids along development depends on ontogenetic, phylogenic and environmental parameters. The expression patterns of FA metabolism genes have not been characterized in developing fish embryos nor compared to lipid class profiles. Full lipid metabolism only occurred after 
hatching, as revealed by alterations in lipid profiles and FA gene expression. Nonetheless, transcriptional changes of some FA genes were already present in embryos at notochord formation. Many genes displayed an expression profile opposed to the decrease of lipids along the development, while others responded solely to starvation. Transcription of most genes involved in FA metabolism had a strong correlation to PPARs mRNA levels $(\alpha 1, \alpha 2, \beta, \gamma)$. The comparison of mRNA expression of the genes with the lipid profiles produced new insights into the FA metabolism and regulation during the development of turbot larvae, providing the basis for future studies including comparative approaches with other vertebrate species.

Keywords: development - embryo - fatty acids - fish larvae - gene transcription - lipid metabolism - peroxisome proliferator activated receptors - Scophthalmus maximus

\section{Introduction}

Dietary long chain polyunsaturated fatty acids (PUFAs) are very important to the nutritional health, physiology and reproduction of vertebrates (Burr, 1981; Simopoulos, 2000) and of crucial importance in early development, due the occurrence of impressive morphological and physiological changes (Tocher, 2003). Highly unsaturated fatty acids (HUFAs) have long been recognized as essential components in fish larval diets (Sargent et al., 1999), playing both an energetic or structural role, depending on the lipid class molecules they are incorporated in. As components of phospholipids (PL) integrated in cell membranes, docosahexaenoic (22:6n-3) and arachidonic (20:4n-6) acids are particularly required for proper neural development and function (Lauritzen et al., 2001).

Peroxisome proliferator activated receptors (PPARs) are involved in many processes related to ontogenesis, such as skeletal formation and differentiation, cell proliferation and epithelial cell growth and differentiation (Michalik et al., 2002; Burdik et al., 2006), lipid metabolism regulation, lipid transport, lipid and glucose oxidation, adipogenesis, lipid homeostasis, (Jump, 2002; Varga et al., 2011; Cour Poulsen et al., 2012; Cho et al., 2012) peroxisomal biogenesis (Schrader et al., 2012) and immune functions (Kostadinova et al., 2005). PUFA, oxidized PUFA and eicosanoids are ligands of all PPAR isosoforms in mammals and amphibians (Hihi et al., 2002) thereby serving as major transcriptional sensors of fatty acids (FA) (Jump, 2008; Xu et al., 1999; Schupp and Lazar, 2010). Interestingly, the three PPAR subtypes display distinct but overlapping expression and functions (Cour Poulsen et al., 2012). In mammals, PPARa and $\mathrm{PPARb}$ activate lipid catabolism by regulating expression of target genes encoding enzymes involved in peroxisomal and mitochondrial b-oxidation of FA, the former mainly in liver and 
1 the second ubiquitously distributed (Wang et al., 2008; Mandard et al., 2004), while PPARg controls lipid accumulation and regulates adipogenesis and osteogenesis (Nedergaard et al., 2005; Ji et al., 2011). It is not very clear whether PPARs have a similar role in mice and humans and to what extent the regulation of PPAR target genes is shared between the two species (Rakhshandehro et al., 2009). Whether the repertoire of PPAR target genes in teleosts is similar to that of mammals is even more uncertain. Compounds that induce proliferation of peroxisomes in rodents, such as fibrate drugs, halogenated hydrocarbons, plasticizers, herbicides and pesticides, may have small or no effect in other species (Lake et al., 1989) due to differences in relative expression of PPARa (Kliewer et al., 1994; Tugwood et al., 1998). Moreover, affinities of the ligands to the receptors can vary considerably among species and PPAR isotypes, mainly due to differences in the ligand binding domain (Krev et al., 1997). In mammals, PPARs consist of three isotypes, PPAR $\alpha, \beta$, and $\gamma$ while in teleosts an additional PPAR $\alpha$ is present due to the teleost specific whole genome duplication (Robinson-Rechavi et al., 2009).

Turbot is an economically important fish species in Spain, France and Portugal. The Food and Agriculture Organization of the United Nations estimated the world aquaculture production in 2009 as 69,557 T (FAO, 2011). Nevertheless, continued research and development effort is required in various areas, namely the fry production, with the aim of increasing larval survival rates and reliability of the process. Various malformations (impaired eye migration, anomalies in visual and central nervous system development, skeletal deformities), malpigmentation, decreased growth and poor feeding rates, reduction of stress tolerance and immune system efficiency, and unexpected high mortality rates are some of the problems faced - many of them related to larvae or broodstock nutritional problems related to HUFAs (Estevéz et al., 1995; Izquierdo et al., 1996; Rainuzzo et al., 1997; Naes and Lie 1998; Estevez et al., 1999; Schields et al., 1999; Hamre et al., 2007; Sargent et al., 1999).

In turbot eggs, lipids are present in two distinct forms, namely in the yolk and in the oil globule (Silversand et al., 1996). Lipoprotein yolk lipids are primarily polar lipids, especially phosphatidylcholine and phosphatidylethanolamine (Wiegand, 1996). In contrast, the oil globule consists of neutral lipids such as triglycerides (TG), sterol esters (SE) and wax esters (WE) (Wiegand, 1996). It was estimated that 55 to $60 \%$ of the lipids in turbot eggs are confined to the oil globule (Silversand et al., 1996). PL appear to constitute 40 to $50 \%$ of the total lipids present in turbot eggs (Devauchelle et al., 1988; McEnvoy et al., 1993; Planas et al., 1993). Since no PL are present in the oil globule, it is reasonable to suggest that they are exclusively in the yolk and that yolk lipid of turbot eggs, to a large extent, consist of PL (Silversand et al., 1996). 
1 Molecular approaches may be helpful to clarify various aspects of FA metabolism in fish

2 development as well as to identify physiological differences between distinct phylogenetic

3 clades (Castro et al., 2011; Castro et al., 2012; Morais et al., 2012). Clarifying species specific nutritional requirements, effects of nutrients deficiency and starvation, and response to chemical contaminant exposure are important steps to understand the mechanisms, control and regulation of lipid metabolism. In this study, the mRNA transcription was analyzed for the four isoforms of $\operatorname{PPAR}(\alpha 1, \alpha 2, \beta$ and $\gamma)$ and for 24 genes involved in various pathways of FA metabolism during the early development of turbot larvae under starving conditions, spanning the period from notochord formation to 9 days post fertilization (dpf). In parallel, the lipid profile was investigated including measurements of total lipids, main lipid classes and FAs fractions. The aim of the study was to compare the lipid profile with the mRNA expression pattern of genes involved in the FA metabolism during the early larval stages of turbot. Here we provide for the first time a comprehensive molecular and analytical snapshot of FA metabolism and regulation during the development of turbot larvae, which should serve as a solid basis for future studies in turbot and other teleost fish, but also for vertebrate classes in comparative approaches.

\section{Material and methods}

\subsection{Egg Incubation and Larval Rearing}

Fertilized eggs of Scophthalmus maximus were obtained from a commercial hatchery (Insuiña, Pescanova S.A.) at Mougás - Spain. Larvae were reared from fertilized eggs to $9 \mathrm{dpf}$ in $60 \mathrm{~L}$ fibre glass tanks in artificial salt water (35 psu) with gentle and constant aeration at $15 \pm 1^{\circ} \mathrm{C}$. $50 \%$ of the artificial salt water was changed daily. Larvae were not feed after mouth opening. Samples were collected at 4 key developmental events: notochord formation ( $2.5 \mathrm{dpf})$, hatching (4.5 dpf), mouth opening (7 dpf) and 50\% mortality (9 dpf) for yolk sac and oil globule measurements, lipid and FA analysis and molecular biology.

\subsection{Yolk sac and oil globule measurements}

Fifteen to twenty eggs/larvae were photographed under a microscope (Olympus IX71®) at each developmental point in order to measure yolk sac and oil globule. Yolk sac volume was calculated from length and width measures assuming a prolate ellipsoid (4/3 $\pi a 2 b)$, where $a$ is the equatorial radius and $b$ is the polar radius). Oil globule volume was calculated from the diameter assuming a spherical form.

\subsection{Lipid Classes and FA Analysis}

Lipid extraction was performed following Blight and Dyer (1959). Total lipid content was determined gravimetrically in duplicate samples of 175-400 larvae/eggs. Five lipid classes were quantified on the total lipids fraction: triglycerides (TG), phospholipids (PL), sterol esters + wax 
esters (SE+WE), sterols (SL), and free fatty acids (FFA). Lipid classes were analysed by thin layer chromatography-densitometry using the Freeman and West (1966) plate staining method. Tripalmitin, cholesterol, cholesterol palmitate and palmitic acid (Sigma) were used as standards for TG, SL, SE+WE and FFA, respectively. PL were quantified following Holland and Gabbot (1971) and Hausen and Grasshoff (1983). SE and WE could not be separated by the solvent mixture and are therefore reported together as a sum. FA were transesterified to methyl esters on total lipid extracts with methanolic hydrogen chloride (Christie, 1982) and, subsequently analysed by gas chromatography, using a programmed-temperature vaporizer injector (PVT, Perkin-Elmer) in the solvent split mode, as described by Herraiz et al. (1987). Henecosanoic acid (21:0) was used as internal standard. Duplicate samples were analysed both for lipid classes and FA analysis.

\subsection{RNA isolation and cDNA synthesis}

Three samples of 50 to 100 pooled eggs or 25 to 30 pooled larvae were collected at each sampling point. RNA extraction was performed using an Illustra RNAspin mini isolation kit (GE Healthcare). RNA integrity was verified on $1 \%$ agarose gels stained with GelRed (Biotium). RNA concentrations were measured with a Qubit fluorometer platform (Invitrogen) and the Quant-IT RNA BR kit (Invitrogen). The same concentration of total RNA ( $1 \mu \mathrm{g})$ was used per sample. Conversion of total RNA into first strand cDNA was performed using the iScript cDNA synthesis kit (Bio-Rad) following the manufacturer recommendations.

\subsection{Isolation of gene sequences in turbot}

Partial sequences of the target genes in turbot were obtained through a degenerate RT-PCR strategy. Degenerate primers (sequences available upon request) were designed based on sequences of the same target genes from other teleost species obtained in databases (Ensemble, NCBI). Block Maker (Henikoff et al., 1995) and Codehope (Rose et al., 1998) software's were used to find conservative sequences on the aligned input sequences and select degenerated primers. Phusion-Taq (Finnzymes, Finland) was used to amplify sequences between each pair of primers. Two microliter of a 1:10 diluted cDNA was used in PCR reactions with the following cycle conditions: $98^{\circ} \mathrm{C} 10 \mathrm{sec}, 55^{\circ} \mathrm{C} 5 \mathrm{sec}, 72^{\circ} \mathrm{C} 30 \mathrm{sec}$ for 40 cycles. PCR products were separated on $1 \%$ agarose gels, and single bands were cut and gel-purified using the GFX PCR DNA and Gel Band Purification kit (GE healthcare). Purified PCR products were forwarded for automated sequencing at StabVida (Portugal). Sequences were deposited on GenBank (NCBI) (S1).

\subsection{Quantitative gene expression}

Gene expression levels were determined by real-time PCR on an QQ5 real-time thermal cycler (Bio-Rad) using iQ SYBR Green Supermix (Bio-Rad). Two microliter of a 1:10 diluted cDNA 
was used in PCR reactions with the following cycle conditions: $94^{\circ} \mathrm{C} 30 \mathrm{sec}, 55^{\circ} \mathrm{C} 30 \mathrm{sec}, 72^{\circ} \mathrm{C}$ $30 \mathrm{sec}$ for 40 cycles. Three calibrators +4 blanks were run in every 96 -well plate. Real-time primers were designed using Beacon Designer software version 7.51 (Premier Biosoft) to outflank intron conserved locations. Primer characteristics and amplicon size are listed at the Supplementary Material (Table S1). Target gene expression was normalized through geometric averaging of multiple internal control genes using GeNorm Software (Vandesompele et al., 2002). From 8 normalizing genes analyzed - EF1a, 18S, UB2L3, RPL8, $\beta$-actin, GAPDH, TBP and TubB2C -5 were chosen according to the GeNorm algorithm: EF1a, 18S, UB2L3, RPL8 and $\beta$-actin. Gene expression (mean of 2 replicates) of the 27 target genes (Table $\mathrm{S} 1$ ) is presented relatively to the expression at notochord formation.

\subsection{Statistics}

One-way ANOVA, followed by Tuckey's post-hoc test, were used to compare data among different developmental stages. When some of the ANOVA assumptions (i.e. normality and homoscedasticity) were not met by data, the Kruskal-Wallis one-way analysis of variance on ranks were used followed by Dunn's test.

Principal components analysis (PCA) was employed to study the inter-correlations of the variables (transcription of 27 genes) by clustering them into common factors. The variables within each factor are highly correlated and each factor explains a different part of the total variance in the data. Factors were Varimax rotated and Kaiser normalized. Correlations between each PPARs and the various target genes are presented graphically using CIRCOS software (Krzywinski et al., 2009).

\section{Results}

\subsection{Yolk sac and oil globule volume}

Yolk sac and oil globule dimensions are presented in Table 1. At hatching, the yolk sac was $0.278 \pm 0.020 \mu 1$ and was almost entirely consumed from hatching to mouth opening $(p<0.01)$ (Fig. 1A). At mouth opening, less than one tenth of its original volume was still present $(\mathrm{p}<$ 0.05), surrounding the oil globule (Fig. 1B). By day 9, the yolk sac was completely consumed (Fig. 1C). The oil globule volume remained constant until hatching. From hatching on, it started to be consumed at a linear rate until the end of the experimental period $(p<0.05)$. At mouth opening, half of its original volume was still present, and by $9 \mathrm{dpf}$, it was reduced to $1.02 \pm 0.36$ $\mathrm{nl}$ (Table 1). At this point, the variability of the oil globule volume was quite large since some larvae presented a visible oil globule of near $1 / 5$ of its volume measured at notochord formation (Fig. 1C), while others did not have it at all. Values in between these extremes were rare. 
2 3.2. Lipid content, lipid classes and fatty acids

3 Total lipid content was stable between notochord formation and hatching, and started to decline 4 significantly $(\mathrm{p}<0.05)$ at linear rate from hatching until the last stage at $9 \mathrm{dpf}($ Table 1$)$. All

5 lipid classes remained constant from notochord formation to hatching (Table 2). The most 6 abundant lipid classes in eggs and newly hatched larvae were PL followed by TG, while the 7 least abundant was FFA. From hatching until 9 dpf (50\% mortality), TG and SE+WE content decreased significantly $(\mathrm{p}<0.05)$. PL, SL and FFA increased from hatching to mouth opening $(\mathrm{p}<0.05$ for PL and SL). PL content decreased significantly $(\mathrm{p}<0.05)$ from mouth opening until 9 dpf, while SL and FFA level remained constant during the same period. At the last stage ( $9 \mathrm{dpf}$ ), the lipid fraction was almost entirely composed by PL and SL, while TG and SE+WE were reduced to vestigial levels. On what concerns FA with different degrees of desaturation (Table 3), all three groups (SFA, MUFA and PUFA) also maintained their level stable from notochord formation until hatching. From hatching on, both MUFA and PUFA declined linearly from hatching, with significant differences at mouth opening and $9 \mathrm{dpf}(\mathrm{p}<0.05)$. In contrast, SFA levels remained constant until mouth opening but decreased significantly at $50 \%$ mortality $(p<0.05)$. N-3 PUFA series was the most abundant at the beginning of development, 8 times more abundant than n-6. Both n-3 and n-6 series remain constant from notochord formation to hatching and then declined linearly up to $50 \%$ mortality. At this point, n- 6 series content was almost residual while n-3 was still considerable.

\subsection{Gene expression}

The 27 target genes analysed covered a major number of metabolic pathways related to FA and lipids metabolism, including FA hydrolysis and activation, $\beta$-oxidation, biosynthesis, desaturation, elongation, hydrolysis of TG and PL, FA esterification to TG and PL and nuclear receptors involved on FA metabolism control (Fig. 2).

\subsubsection{FA activation and FA hydrolysis}

Relative expression levels of two fatty acyl-CoA thioesterases (Acots) responsible for FA hydrolysis, and two acyl-CoA synthetase long-chain (Acsls) responsible for FA activation, are presented in Figure 3. Acot7 mRNA expression decreased significantly from notochord formation until hatching $(\mathrm{p}<0.05)$, and returned to its initial level in later larval stages. Acot8 mRNA expression was highest at notochord formation, diminished significantly at hatching and remained constant at this expression level until 50\% mortality $(\mathrm{p}<0.05)$. Acsl2 and Acls 4 
mRNA level did not change during development, with the exception of a higher level $(\mathrm{p}<0.05)$ in Acsl2 at 50\% mortality (Fig. 3).

\subsection{2. $\beta$-Oxidation}

The mRNA expression rate of Acyl-CoA oxidase 1 (Acox 1 ) increased significantly from egg stage to mouth opening, and from there to $50 \%$ mortality $(\mathrm{p}<0.05)$. Carnitine

palmitoyltransferase 1a-related (Cptla-rel; Boukouvala et al., 2010) remained unchanged during the whole developmental period (Fig. 3).

\subsubsection{FA Biosynthesis and desaturation}

The mRNA expression FA synthetase (Fasn) was constant until mouth opening, but increased twice at $50 \%$ mortality ( $\mathrm{p}<0.05$; Fig. 4). The transcription of 3 FA desaturases, stearoyl-CoA desaturase members 1a and $1 \mathrm{~b}(S c d 1 a, S c d 1 b)$ and FA desaturase 2 (Fads2) increased significantly between hatching and mouth opening ( $<<0.05$; Fig. 4), while Fads 2 and Scd1b further increased at $50 \%$ mortality $(\mathrm{p}<0.05)$. Fads 2 expression at mouth opening was around 12 -fold greater than at notochord formation, and 25 -fold greater at $50 \%$ mortality.

\subsubsection{FA elongation}

All 6 FA elongases (Elovl) increased their expression along the developmental stages (Fig. 5), with significant differences $(\mathrm{p}<0.05)$ between hatching and mouth opening (with the exception of Elovla: significant against notochord formation, $\mathrm{p}<0.05)$. Elovl4b expression rate increased the most, nearly 25 -fold from eggs stage to 50\% mortality. Elovl1, Elovl4a, Elovl4b and Elovl6 expression rate did not change between mouth opening and 50\% mortality. However, the expression of Elov5 and Elovl6-like gene increased significantly between mouth opening and $50 \%$ mortality $(\mathrm{p}<0.05)$, with a 9- fold difference for Elovl6-like gene from notochord formation until end of the experiment.

\subsubsection{Hydrolysis of $T G$ and $P L$}

The expression rate of the various lipases displayed different patterns with development. While lipoprotein lipase $(L p l)$ expression rate increased during the whole period with significant changes between notochord, mouth opening and 50\% mortality $(\mathrm{p}<0.05)$, lipase A (LipA) and lipase E (LipE) remained at the same mRNA transcription level along development (Fig. 6). Hepatic lipase $(\mathrm{LipH})$ expression remained stable until mouth opening and then increased abruptly 13 -fold afterwards $(\mathrm{p}<0.05)$. 


\subsubsection{FA esterification to $T G$ and $C E$}

Diacylglycerol O-acyltransferase homolog 1 (Dgat1) expression remained stable from notochord formation to mouth opening and then increased 1.5 -fold at $50 \%$ mortality $(p<0.05)$, whereas Dgat2 decreased from notochord formation to hatching and increased to 2-fold at mouth opening and 50\% mortality $(\mathrm{p}<0.05$; Fig. 7$)$.

Sterol O-acyltransferase2 (Soat2) displayed a decreased mRNA expression as development progressed, from notochord formation to hatching $(\mathrm{p}<0.05)$ and remained constant until $50 \%$ mortality.

\subsubsection{FA metabolism control}

The four analyzed $P P A R$ isoforms displayed different expression patterns along the development. $P P A R \alpha 1$ and $P P A R \gamma$ expression rates increased with significant differences between notochord formation, hatching and mouth opening $(\mathrm{p}<0.05)$. In contrast, $P P A R \beta$ remained steady in all larval stages and, $P P A R \alpha 2$, decreased from notochord formation to hatching $(\mathrm{p}<0.05)$ and then maintained this low mRNA expression level until 50\% mortality (Fig. 8). PPAR $\gamma$ was the gene whose expression increased mostly (90-fold) during the whole experimental period.

\subsection{Principal components analysis}

The principal components analysis extracted two factors, PC1 and PC2 that explained $76.49 \%$ of total data variation (43.46 and 33.03\% respectively) (Fig. 9). Based on the examination of the graphical representation of the factor loadings for each variable, genes were grouped according to their relative positions (Fig. 9). At least three groups were initially defined according to their mRNA expression pattern along the larval development. The most determinant variables were Cpt1a-rel, Elovl5, Elov6l, Fads2, Fasn, LipH and Scd1b for PC1, and were Acot8, LipA, LipE, Soat2 and PPARa2 for PC2 (supplementary material 2 - S2). Group 1 included genes whose transcription tended to increase along the developmental stages, either from NT formation or from hatching on. This group includes PPAR $\alpha 1, P P A R \gamma$, and many genes positively correlated to them or inversely correlated to PPAR 2 2 (Elovl4a, Elovl4b, Elovl5, Elovl6, Elovl6l, Lpl, Scd1a, Scd1b, Fads2, Acox). Group 2 includes genes whose transcription remained stable along development (PPAR $\beta$, Cpt1a-rel, Acls2), and whose transcription increased only at $50 \%$ mortality of the starved larvae (Fasn, LipH, Dgat1 and Acsl4) and those whose transcription was quite stable but increased or decreased significantly in some moment during development (Acot7 and Dgat2). Group 3 is composed by those genes whose transcription decreased along 
1 development including PPAR $\alpha 2$ and other genes directly correlated to it (Soat2, LipA, LipE and 2 Acot8).

3 The correlation factors of the transcription of PPARs with that of the other genes are presented 4 on supplementary material 3 (S3). The correlation of PPAR's transcription to other genes ( $\mathrm{p}<$ $5 \quad 0.05)$ is represented in the diagram of Figure 10. PPAR $\alpha 1$ is the nuclear receptor that was 6 correlated to the highest number of genes, followed by PPAR $\gamma, \operatorname{PPAR} \alpha 2$ and PPAR $\beta$. The 7 analysis demonstrated that many genes were correlated or highly correlated to more than one 8 PPAR (Fig. 10, S3). Two genes were even highly correlated to all 4 PPARs (Elovl4a and 9 Elovl $4 b$ ). Most commonly, genes are related to 3 PPARs (9 genes) or 2 PPARs (6 genes). PPAR $\alpha 1$ and PPAR $\gamma$ correlated together to 17 genes that are mostly involved in FA elongation or desaturation (8 genes).

\section{Discussion}

During embryogenesis and until mouth opening, embryos and larvae are theoretically in optimal nutritional conditions. Yolk and oil globule are considered to contain the nutrients and energy required for an adequate development until the stage of mouth opening. Proteins, PL and cholesterol are present in the yolk to be used as building blocks in new cells, tissues and organs, while TG, SE and WE are present both in the oil globule and in yolk to produce energy (Finn, 1994; Silversand et al., 1996). In our study, the levels of total lipids and lipid classes started to change from hatching to mouth opening (Table 2) and consequently, the transcriptional level in the majority of analysed genes changed significantly at this period (Figs. 3 to 8). These results suggest that the main regulations of lipid metabolism started between hatching and mouth opening at the transcript and lipid level. This outcome is in agreement with previous published studies on lipid content analysis and respirometry in turbot larvae, which pointed out that the start of lipid metabolism occurs by the time of hatching (Finn, 1994; Finn et al., 1996). It was suggested that fish species with oviparous progeny evolved two types of energetic strategies for their offspring (Finn, 1994). Type I which includes Atlantic cod and Atlantic halibut, involves only deposition of yolk in the egg, that is resorbed continuously by embryos and larvae, while in type II case, oil globule is only consumed when yolk is exhausted. In this later strategy fall turbot and seabass (Dicentrarchus labrax), where free amino acids appeared to be a significant energy substrate during the egg and the early yolksac stages while FA from neutral lipids derived from the oil globule seemed to be the main metabolic fuel after hatching (Finn, 1994; Rønnestad et al., 1998). Also, neutral lipids were 
1 dominant for turbot at hatching, while phospholipids predominated prior to first feeding, in accordance to Rainuzzo et al. (1993).

However, a former transcriptional activity was observed between notochord formation and hatching, where 7 out of 27 genes related to FA metabolism presented significant differences at the transcription level. Those genes are involved in FA metabolism control (PPAR $\alpha 1, \alpha 2)$, FA hydrolysis (Acot7, Acot8), hydrolysis of TG and PL ( $L p l)$, and FA esterification (Soat2, Dgat2). Most of the transcriptional changes were characterized by a higher transcript level at notochord formation as compared to hatching (Acot7, Acot8, Soat2, Dgat2) and included PPAR 2 , which suggested a transcriptional regulation. The altered mRNA expression of genes does not reflect a change in their functionality (Nikinmaa and Rytkoenen, 2011), and the correlation between mRNA expression and enzyme activity is generally low (Vogel and Marcotte, 2012). However, mRNA expression in our study can serve as a first indication at which steps the regulation of the lipid metabolism might be altered during the larval development. In this light, it could be speculated that the decreasing transcript level of Acots at hatching might lead to an increased FA-CoAs pool, which could be used by many other FA metabolism genes at their onset of expression at mouth opening. $\mathrm{Lpl}$ was up-regulated between notochord formation and hatching, which seemed to follow the mRNA expression of PPAR $\alpha 1$ which could be interpreted as the first signs of hydrolysis of TG/PL. Transcriptional changes at early embryonic stages suggested that important processes of FA metabolism would have started already before hatching. Indeed, a decrease in PL and cholesterol content during turbot embryogenesis was reported by Finn et al. (1996) in a more detailed study on lipid sources. According to our results, PL hydrolysis might be attributed to Lpl activity.

PUFA and MUFA decreased significantly between hatching and mouth opening. Interestingly, the genes related to FA elongation (all Elovs) and FA desaturation (Fads2, Sdc1a, Sdc1b) (Fig. 4 and 5) showed the opposite pattern of unsaturated FA during the same period, being significantly up-regulated at mouth opening. It is feasible that the FA profile contained in the lipid reserves matched the initial demands of the embryos and larvae and, that at a certain developmental time, the larvae started to elongate and desaturate FA, to produce, to some extent, some of those FA no long available in the reserves. Here, the first signs of FA retailoring in turbot larvae were observed at the stage between hatching and mouth opening. In agreement with this, a great increase in desaturase ( $\Delta 6$ desaturase/Fads2) and elongase (Elovl5) expression is also observed in tuna larvae (Thunnus thymus) after hatching (Morais et al., 2011). From notochord formation to mouth opening PUFA are heavily used for the formation of nervous tissue in turbot larva, including eyes which are fully functional at mouth opening (AlMaghazachi and Gibson, 1988). Most Elovls increased their activity 1.5 to 2.5 -fold from 
1 hatching to mouth opening, while Elovl $4 b$ increased more than 6-fold. At mouth opening the

eyes of turbot larvae get functional to help on foraging behaviour and in accordance, analysis by whole-mount in situ hybridisation in zebrafish embryos showed that Elovl $4 b$ is specifically expressed in photoreceptor cells of retina (Monroig et al., 2010). Furthermore, fads-like gene transcripts in nibe croaker (Nibea mitsukurii) larvae fed on oleic acid-enriched Artemia were significantly higher than those in larvae fed on 100\% 22:6n-3-enriched Artemia, indicating that the Fads 2 gene was controlled by negative feedback from the quantity of $22: 6 \mathrm{n} 3$ stored in the larval body (Yamamoto et al., 2010). This finding is also in accordance with our data, where the decrease of PUFA was accompanied by an increase in FA desaturases. In contrast to our results, where Elovl5 pattern was also inverse to FA decrease, no significant differences were observed in the transcript levels of the Elovl5 gene in nibe croaker fed on 22:6n-3-enriched Artemia (Yamamoto et al., 2010).

From hatching to mouth opening, energetic lipids (TG, SE) were consumed, whereas structural lipids (PL, SL) slightly increased. Surprisingly, most genes involved in hydrolysis of TG, PL and SE remained unchanged during this period (LipA, LipH, LipE). Lpl was the only lipase with transcriptional changes during this period and could have played an important role in the catabolism of energetic lipids. Accordingly, Acoxl expression increased from hatching, and later after mouth opening, in parallel to $L p l$ mRNA expression, which may be indicative of $\beta$ oxidation at the protein level and FFA generated by TG hydrolysis (Owen et al., 1979). Therefore, evidence is present at transcriptional level that hydrolysis of TG and PL started between hatching and mouth opening. However, other lipases might be involved in the hydrolysis of SE in the early stages of larval development of turbot, e.g. patatin-like enzymes as in birds (Saarela et al., 2008).

Genes involved in the FA esterification to TG, PL and SE (Dgat1, Dgat2, Soat2) showed different expression patterns between hatching and mouth opening. Soat 2 decreased in parallel to the decrease of TG and SE. Free cholesterol is esterified into SE by Soats in the endoplasmic reticulum and stored in lipid droplets (Ikonen, 2008). In humans, SOAT2 is limited to the liver and intestine, converting free cholesterol to esters destined for VLDL assembly in the liver or to chylomicron assembly in the intestine (Leon et al., 2005). In turbot larvae, Soat2 seems to have an initial role before hatching and loses significance afterwards. At hatching, turbot hepatocytes contain few endoplasmic reticulum membranes (Segner et al., 1994) and the intestine is not functional yet, which may justify low Soat 2 transcription levels.

During the last stage of development (mouth opening to 50\% mortality), larvae were in starvation and consequently all lipid classes diminished significantly. Especially, mRNA expression of LipH, Fasn and Dgat1 seemed to be nutritionally regulated, by the decreasing 
1 level of substrate (negative feedback) during starving conditions. The transcription of these genes was stable until mouth opening, but increased when extreme starvation conditions were reached. LipH hydrolyzes specifically phosphatidic acid to produce 2-acyl lysophosphatidic acid (LPA, a potent bioactive lipid mediator) and a non-specific FA (Aoki et al., 2008; Shinkuma et al., 2010). It has been described that LPA synthesized intracellularly via the pathway of TG or PL biosynthesis can activate PPAR $\gamma$ (Stapleton et al., 2011). It is plausible that LPA resultant from PL and TG catabolism through LipH catalysis might be one of the causes of the strong $P P A R \gamma$ transcription induction occurring between mouth opening and 50\% mortality. The expression of various other genes related to FA synthesis and storage, such as Elovl5, Elovl6l, Scd1b and Fads 2 changed after mouth opening in starving larvae. The expression of these genes had already increased from notochord formation to mouth opening, but starvation further induced their expression levels. In contrast to LipH, Fasn and Dgatl, which seemed to be clearly nutritionally regulated, it is impossible to differentiate if the up-regulation of these genes is ontogenetically programmed during these larval stages or, if they might be induced by low levels of a substrate or product. A recently cloned $\triangle 4 F a d$ gene in Solea senegalensis was found to be highly responsive to low levels of n-3 long chain PUFA (Morais et al., 2012) and a Fads 2 gene in N. mitsukurii was also controlled by negative feedback from the amount of substrate (Yamamoto et al., 2010). However, the possibility of a developmentally fixed pattern of both Fads and Elovls to ensure right 22:6n3 levels for neurogenesis independently of dietary supply must not be discharged.

Between mouth opening and 50\% mortality, significant changes were also observed in Acox 1 mRNA expression (Fig. 3), which might indicated that during starvation $\beta$-oxidation of very long and long chain FAs in the peroxisome contributed to the energy production. It is also possible that Acoxl was to be used not only for FA oxidation but also for FA elongation/shortening, through the Sprecher's shunt (Sprecher, 1992) to produce DHA in the peroxisome, since an intense transcription of Elovls (including Elovl5 and Elovl4b) and Fads was detected at the final stage of starvation. Interestingly, the mRNA expression of the different PPARs did not change at the end of the starvation period. This might imply that a transcriptional response of PPARs is not involved in the regulatory response to starvation. The regulatory response might be a direct effect on the target genes driven by the absence of substrates or by other metabolic signals of starvation. In this aspect, the regulation of fasting in teleost fish might be different from mammals. It has been shown in PPAR $\alpha$ null mice that PPAR $\alpha$ is especially important for the adaptive response to fasting by stimulating hepatic FA oxidation and ketogenesis (Kersten et al., 1999; Hashimoto et al., 2000; Leone et al., 1999). 
1 In contrast to the starvation period, the different PPARs demonstrated different expression 2 patterns between notochord formation and mouth opening. Transcriptional activity of PPAR 2 3 was high at notochord formation and decreased 4-fold to a low value from then on. The mRNA expression profile of PPAR $\alpha 1$ was the opposite of PPAR $\alpha 2$, and increased significantly from notochord to hatching and mouth opening. Fernández et al. (Fernandez et al., 2011) observed a strong increase in PPAR $\alpha 1$ transcriptional activity in Sparus aurata, from days 2 to 7 after hatching, which confirms our data for PPAR $\alpha 1$. The different transcription profile observed on the two PPAR $\alpha$ isoforms is probably indicative of a gene sub-functionalization. In mammals it is well known that high levels of n-3 PUFA suppress transcription of various enzymes of FA metabolism e.g. Elovl6, Fasn, Scd1, through ligation to PPAR $\alpha$ (Wang et al. 2005; Jump et al., 2006). Interestingly, we observed here that the levels of n-3 PUFA decreased linearly from hatching to $50 \%$ mortality while the mRNA expression of those enzymes increased significantly, as well as others also involved in desaturation, elongation and $\beta$ oxidation of FA (e.g. Fads2, Acox1, Acsl4, Elovl1 and Elovl5). The substrate of these enzymes would possibly be other saturated, monounsaturated and polyunsaturated FA already present, that are transformed in others that perform essential specific functions, taking in to account that vertebrates lack $\Delta 15$ desaturase, that some elongases and desaturases have a very limited efficiency in marine fish (Ghioni et al., 1999; Agaba et al., 2005; Tocher et al., 2003), and that fish are not likely to biosynthesize fatty acids de novo to any significant extent, if they do so at all (Tocher, 2003), from acetyl-CoA and malonyl-CoA precursors.

The principal component analysis revealed that PPAR $\alpha 1$ shared with PPAR $\gamma$ a common group of several lipid metabolic genes (Fig. 9). The group consists of 12 genes, which includes most genes related to FA elongation and desaturation. From all the genes studied, $P P A R \gamma$ was the one that most changed during the experimental period ( $~ 100$-fold). This gene is known to be involved in lipid anabolism regulation but is also required for development of various tissues, namely, placental, cardiac, adipose tissue development and skeletogenesis (Fernandez et al., 2011; Barak et al., 1999).

$P P A R \beta$ activity was stable during the whole developmental period. Similarly, it was reported that the mRNA level of $P P A R \beta$ was not elevated in the jejunum during the postnatal development of the rat (Mochizuki et al., 2001). In the seabream, Sparus aurata, PPAR $\beta$ transcription also seems to be relatively stable during the first 60 days after hatching (Fernandez et al., 2011).

Correlation analysis pinpointed that the transcription of various genes may be controlled by more than one PPAR, more commonly, by two or three PPARs (Fig 10 and S3). PPAR 1 transcription is highly correlated to $P P A R \beta$ and especially to $P P A R \gamma$ and $P P A R \alpha 2$. PPAR $\alpha 1$ and 
$1 P P A R \gamma$ are the nuclear receptors whose transcription correlated to more genes simultaneously.

2 Moreover, all genes correlated to $P P A R \alpha 2$ transcription were also inversely correlated to

3 PPAR $\alpha 1$ and PPAR $\gamma$, which might indicate that they co-ordinately modulate the transcription of

4 various genes together, but in opposite directions. To our knowledge, this is the first study in a

5 teleost fish species providing evidence for a regulation of FA metabolism genes by a joint action

6 of different PPARs. In other animal models, it is known that some genes are regulated by more

7 than one PPAR. It has been suggested that Acox 1, L-Fabp and other PPAR-dependent genes

8 may be co-ordinately modulated in the small intestine of developing rats, during postnatal

9 development, by the disproportional expression of PPAR $\alpha$ over PPAR $\beta$ (Mochizuki et al., 2001). Also, the human LPL promoter is regulated differentially by the binding of PPAR $\alpha$ or PPAR $\gamma$ together with the retinoic acid X receptor (RXR) heterodimer (Schoonjans et al., 1996). Also, thiazolidinediones predominantly affected adipocyte LPL production through activation of $\operatorname{PPAR} \gamma$, while fibrates exerted their effects mainly in the liver via activation of PPAR $\alpha$ (Schoonjans et al., 1996). Genes that were correlated uniquely to $P P A R \gamma$ (Fig 10 and S3) were related to FA de novo synthesis (Fasn) and to PL hydrolysis (LipH). Genes correlated to PPAR $\beta$ alone are related to FA activation and deactivation (Acsl2 and Acot7). In accordance to our results, three developmental periods in the early turbot larvae were characterized as follows (Figure 11):

a) Embryos - from notochord formation to hatching - the oil globule was not consumed, analytical lipid parameters were constant, but the first transcriptional alterations in lipid metabolism genes were observed. First transcriptional signs for hydrolysis of TG and PL ( $L p l$ ) were detected together with a high expression of PPAR $\alpha 2$.

b) Eleutheroembryos - larvae feeding on endogenous reserves - lipids started to be metabolized, which could be observed by the decrease of the lipid classes levels related to energy storage (TG, SE+WE, MUFA and PUFA) as well as the reduction of oil globule and yolk sac volumes. Moreover, structural lipids (i.e PL, SL) increased significantly during this stage. Many genes related to lipid anabolism and catabolism were up-regulated, and no gene was down-regulated during this stage. First transcriptional signs for FA $\beta$-oxidation (Acoxl), FA desaturation (Fads2, Scd1 a, Scd1b) and FA elongation (all Elovls) were observed.

c) Larvae - mouth opened but not fed - oil globule was consumed until exhaustion. The level of energy storage lipids (SE+WE and TG) decreased until exhaustion. PL decrease, and only SL levels remain steady. LipH, Dgat1 and Fasn, whose transcriptional activity did not change during the whole development, responded strongly to starvation at this stage.

\section{Conclusions}


2 In conclusion, full lipid metabolism only occurs after hatching, as revealed by alterations in lipid 3 profiles and FA gene expression; Transcriptional changes of some FA genes were already

4 present in embryos at notochord formation; Many of the studied genes displayed an expression

5 profile, which is opposed to the decrease of lipids along the development due to the

6 consumption of yolk reserves and oil globule, suggesting a negative feedback of substrates on

$7 \quad$ FA gene expression; Other genes (e.g. LipH, Fasn and Dgat1) were not altered during

development, but responded strongly to starvation and; Transcription of most genes involved in

FA metabolism had a strong correlation to PPARs mRNA levels $(\alpha 1, \alpha 2, \beta, \gamma)$ and evidence is suggested for an orchestrated control by two or three PPARs isoforms.

Acknowledgements. This work was developed under the research project

PTDC/MAR/68885/2006, funded by the Portuguese Foundation for Science and Technology

\section{References}

Agaba M.K., Tocher, D.R., Zheng, X., Dickson, C.A., Dick, J.R., Teale, A.J., 2005. Cloning and functional characterisation of polyunsaturated fatty elongases of marine and freshwater teleost fish. Comp. Biochem. Physiol., 142, 342-352.

Al-Maghazachi, S., Gibson, R., 1984. The developmental stages of larval turbot, Scophthalmus maximus (L.). J. Exp. Mar. Biol. Ecol. 82, 35-51.

Aoki, J., Inoue, A., Okudaira, S., 2008. Two pathways for lysophosphatidic acid production. Biochim. Biophys. Acta 1781, 513-518.

Barak, Y., Nelson, M.C., Ong, E.S., Jones, Y.Z., Ruiz-Lozano, P., Chien, K.R., Koder, A., Evans R.M., 1999. PPAR gamma is required for placental, cardiac, and adipose tissue development. Mol. Cell 4, 585-595.

Blight, E.G., Dyer, W.J., 1959. A rapid method for total lipid extraction and purification. Can. J. Biochem. 37, 911-917.

Boukouvala, E., Leaver M.J., Favre-Krey, L., Theodoridou, M., Krey, G., 2010. Molecular characterization of a gilthead sea bream (Sparus aurata) muscle tissue cDNA for carnitine palmitoyltransferase 1B (Cpt1b). Comp. Biochem. Physiol. 157B, 189-197.

Burdick, A.D., Kim, D.J., Peraza, M.A., Gonzalez, F.J., Peters, J.M., 2006. The role of peroxisome proliferator-activated receptor-beta/delta in epithelial cell growth and differentiation. Cell Signal. $18,9-20$.

Burr, G.O., 1981. The essential fatty acids fifty years ago. Prog Lipid Res 20:27-29.

Castro, L.F.C., Wilson, J.M., Gonçalves, O., Galante-Oliveira, S., Rocha, E., Cunha, I., 2011. The evolutionary history of Stearoyl-CoA desaturase gene family in vertebrates. BMC Evol. Biol. 11, 132. 
Castro, L.F.C., Monroig, O., Leaver, M.J., Wilson, J., Cunha, I., Tocher, D.R., 2012. Functional desaturase Fads1 $(\Delta 5)$ and Fads2 $(\Delta 6)$ orthologues evolved before the origin of jawed vertebrates. PlosOne 7, e31950.

Cho, H.K., Kong, H.J., Kim, H.Y., Cheong, J., 2012. Characterization of Paralichthys olivaceus peroxisome proliferator-activated receptor- $\alpha$ gene as a master regulator of flounder lipid metabolism. Gen. Comp. Endocrinol. 175, 39-47.

Christie, W.W., 1982. Lipid analysis. Pergamon Press, Oxford.

Cour Poulsen, L., Siersbæk, M., Mandrup, S., 2012. PPARs: Fatty acid sensors controlling metabolism. Semin. Cell. Dev. Biol. http://dx.doi.org/10.1016/ j.semcdb.2012.01.003.

Devauchelle, N., Alexandre, J.C., Le Corre, N., Letty, Y., 1988. Spawning of turbot (Scophthalmus maximus) in captivity. Aquaculture 69, 159-184.

Estévez, A., Kanazawa, A., 1995. Effect of (n-3) PUFA and vitamin A Artemia enrichment on pigmentation success of turbot, Scophthalmus maximum (L.). Aquacult. Nutr. 1, 159-168.

Estévez, A., McEvoy, L.A., Bell, J.G., Sargent, J.R., 1999. Growth, survival, lipid composition and pigmentation of turbot (Scophthalmus maximus) larvae fed live-prey enriched in arachidonic and eicosapentaenoic acids. Aquaculture 180, 321-343.

FAO. 2011. http://www.fao.org/fishery/culturedspecies/Psetta maxima/en

Fernandez, I., Darias, M., Andree, K.B., Mazurais, D., Zambonino-Infante, J.L., Gisbert, E., 2011. Coordinated gene expression during gilthead sea bream skeletogenesis and its disruption by nutritional hypervitaminosis A. BMC Dev. Biol. 11, 7.

Finn, R.N., 1994. Physiological Energetics of Developing Marine Fish Embryos and Larvae, Ph.D. Thesis, Zoological Institute, University of Bergen, Norway.

Finn, R.N., Fyhn, H.J., Henderson, R.J., Evjen, M.S., 1996. Sequence of catabolic substrate oxidation and enthalpy balance of developing embryos and yolk-sac larvae of turbot (Scophthalmus maximus L.). Comp. Biochem. Physiol. 115A, 133-151.

Freeman, C.P., West, D., 1966. Complete separation of lipid classes on a single thin layer plate. J. Lipid Res. 7, 324-327.

Ghioni, C., Tocher, D.R., Bell, M.V., Dick J.R., Sargent, J.R., 1999. Low C18 to C20 fatty acid elongase activity and limited conversion of stearidonic acid, $18: 4 n 3)$, to eicosapentaenoic acid, 20:(5n3), in a cell line from the turbot, Scophthalmus maximus. Biochim. Biophys. Acta, 1437, 170-181.

Hamre, K., Holen, E., Moren, M., 2007. Pigmentation and eye migration in Atlantic halibut (Hippoglossus hippoglossus L.) larvae: new findings and hypotheses, Aquacult. Nut. 13, 65-80.

Hashimoto, T., Cook, W.S., Qi, C., Yeldandi, A.V., Reddy, J.K., Rao, M.S., 2000. Defect in peroxisome proliferator-activated receptor alpha-inducible fatty acid oxidation determines the severity of hepatic steatosis in response to fasting. J. Biol. Chem. 275, 28918-28928.

Hausen, H.P., Grasshoff, K., 1983. Automated chemical analysis, in: Grasshoff, K., Ehrhardt, M., Kremling, K. (eds.), in: Methods of seawater analysis, Verlag Chemie, Weinheim, pp. 347-395.

Herraiz, M., Reglero, G., Loyola, E., Herrais, T., 1987. Sampling of volatile componentes using a PVT in the solvente split mode. J. High Res. Chromatog, 10, 598-602.

Henikoff, S., Henikoff, J.G., Alford, W.J., Pietrokovski, S., 1995. Automated construction and graphical presentation of protein blocks from unaligned sequences. Gene 163, 17-26.

Hihi, A.K., Michalik, L., Wahli, W., 2002. PPARs: transcriptional effectors of fatty acids and their derivatives. Cell. Mol. Life Sci. 59, 790-798.

Holland, D.L., Gabbott, P.A., 1971. A microanalytical scheme for the determination of protein, carbohydrate, lipid and RNA levels in marine invertebrate larvae. J. Mar. Biol. Ass. UK 51, 659668.

Ikonen, E., 2008. Cellular cholesterol trafficking and compartmentalization. Nature Rev. 9, 125-138. 
Izquierdo, M.S., 1996. Essential fatty acid requirement of marine fish larvae. Aquacult. Nutr. 2,183-191. Ji, H., Liu, Y., Zhao, X., Zhang, M., 2011. N-acetyl-L-cysteine enhances the osteogenic differentiation and inhibits the adipogenic differentiation through up regulation of Wnt $5 \mathrm{a}$ and down regulation of PPARg in bone marrow stromal cells. Biomed. Pharmacother. 65, 369-374.

Jump, D.B., 2002. The biochemistry of n-3 polyunsaturated fatty acids. J. Biol. Chem. 277, 8755-8758.

Jump, D.B., 2008. N-3 polyunsaturated fatty acid regulation of hepatic gene transcription. Curr. Opin. Lipidol. 19, 242-247.

Jump, D.B., Botolin, D., Wang, Y., Xu, J., Christian, B., 2006. Fatty acids and gene transcription. Scand. J. Food Nut. 50, 5-12.

Kersten, S., Seydoux, J., Peters, J.M. Gonzalez, F.J., Desvergne, B., Wahli, W., 1999. Peroxisome proliferator-activated receptor alpha mediates the adaptive response to fasting. J. Clin. Invest. 103, 1489-1498.

Kliewer, S.A., Forman, B.M., Blumberg, B., Ong, E.S., Borgmeyer, U., Mangelsdorf, D.J., Umesono, K., Evans, R.M., 1994. Differential expression and activation of a family of murine peroxisome proliferator-activated receptors. Proc. Natl. Acad. Sci. USA 91, 7355-7359.

Kostadinova, R., Wahli, W., Michalik, L., 2005. PPARs in diseases: control mechanisms of inflammation. Curr. Med. Chem. 12, 2995-3009.

Krey, G., Braissant, O., L’Horset, F., Kalkhoven, E., Perroud, M., Parker, M.G., Wahili, W., 1997. Fatty acids, eicosanoids and hypolipidemic agents identified as ligands of peroxisome proliferatoractivated receptors by coactivator dependent receptor ligand assay. Mol. Endo. 11, 779-791.

Krzywinski, M., Schein, J., Birol, I., Connors, J., Gascoyne, R., Horsman, D., Jones, S., Marra, M., 2009. Circos: An information aesthetic for comparative genomics. Genome Res. 19, 1639-1645.

Lake, B.G., Evans, J.G., Gray, T.J., Körösi, S.A., North, C.J., 1989. Comparative studies on nafenopininduced hepatic peroxisome proliferation in the rat, Syrian hamster, guinea pig, and marmoset. Toxicol. Appl. Pharmacol. 99, 148-160.

Lauritzen, L., Hansen, H., Jorgensen, M., Michaelsen, K., 2001. The essentiality of long chain n-3 fatty acids in relation to development and function of brain and retina. Prog. Lipid Res. 40, 1-94.

Leon, C., Hill, J., Wasan, K., 2005. Potential role of acyl-coenzyme A: cholesterol transferase (ACAT) inhibitors as hypolipidemic and antiatherosclerosis drugs. Pharm. Res. 22, 1578-1588.

Leone, T., Weinheimer, C., Kelly, D., 1999. A critical role for the peroxisome proliferator-activated receptor alpha (PPARalpha) in the cellular fasting response: the PPARalpha-null mouse as a model of fatty acid oxidation disorders. Proc. Natl. Acad. Sci. USA 96, 7473-7478.

Mandard, S., Müller, M., Kersten, S., 2004. Peroxisome proliferator activated receptor $\alpha$ target genes. Cell. Mol. Life Sci. 61, 393-416.

McEvoy, L., Holland, D., McEvoy, J., 1993. Effect of spawning fast on lipid and fatty acid composition of eggs of captive turbot (Scophthalmus maximus L.). Aquaculture 114, 131-139.

Michalik, L., Desvergne, B., Dreyer, C., Gavillet, M., Laurini, R.N., Wahli, W., 2002. PPAR expression and function during vertebrate development. Int. J. Dev. Biol. 46, 105-114.

Mochizuki, K., Suruga, K., Yagi, E., Takase,S., Goda, T., 2001. The expression of PPAR-associated genes is modulated through postnatal development of PPAR subtypes in the small intestine. Biochim. Biophys. Acta 1531, 68-76.

Monroig, O., Rotllant, J., Cerdá-Reverter, J.M., Dick, J.R., Figueras, A., Tocher, D.R., 2010. Expression and role of Elovl4 elongases in biosynthesis of very long-chain fatty acids during zebrafish Danio rerio early embryonic development. Biochem. Biophys. Acta 10, 1145-1154.

Morais, S., Mourente, G., Ortega, A., Tocher, J.A., Tocher, D.R., 2011. Expression of fatty acyl desaturase and elongase genes, and evolution of DHA:EPA ratio during development of unfed larvae of Atlantic bluefin tuna (Thunnus thynnus L.). Aquaculture 313, 129-139. 
Morais, S., Castanheira, F., Martines-Rubio, L., Conceição, L.E.C., Tocher, D.R., 2012. Long chain polyunsaturated fatty acid synthesis in a marine vertebrate: ontogenic and nutritional regulation of a fatty acid desaturase with D4 activity. Biochem. Biophys. Acta 1821, 660-671.

Næss, T., Lie, Ø., 1998. A sensitive period during first feeding for the determination of pigmentation pattern in Atlantic halibut, Hippoglossus hippoglossus L., juveniles: the role of diet. Aquacult. Res. 29, 925-934.

Nedergaard, J., Petrovic, N., Lindgren, E.M., Jacobsson, A., Cannon, B., 2005. PPAR $\gamma$ in the control of brown adipocyte differentiation. Biochim. Biophys. Acta 1740, 293-304.

Nikinmaa, M., Rytkönen, K.T., 2011. Functional genomics in aquatic toxicology-Do not forget the function. Aquat. Toxicol. 105S, 16- 24.

Owen, O.E., Reichard, G.A., Patel, M.S., Boden, G., 1979. Energy metabolism in feasting and fasting. Adv. Exp. Med. Biol. 111, 169-188.

Planas, M., Labarta, U., Fernandez-Reiriz, M.J., Ferreiro, M.J., Munilla, R., Garrido, J.L., 1993. Chemical changes during development in turbot (Scophthalmus maximus) eggs and larvae, in: Walther, B.T., Fyhn, H.J. (Eds) Physiological and biochemical aspects of fish development. Univ Bergen, Bergen, Norway, pp 269-278.

Rainuzzo, J.R., Reitan, K.I., Olsen, Y., 1997. The significance of lipids at early stages of marine fish: a review. Aquaculture 155, 103-115.

Rainuzzo, J.R., Reitan, K.I., Jørgensen L., 1993. Comparative study on the fatty acid and lipid composition of four marine fish larvae. Comp. Biochem. Physiol. 103, 21-26.

Rakhshandehro, M., Hooiveld, G., Müller, M., Kersten, S., 2009. Comparative analysis of gene regulation by the transcription factor PPARalpha between mouse and human. PLoS One 4:e6796.

Robinson-Rechavi, M., Marchand, O., Escriva, H., Bardet, P.L., Zelus, D., Hughes, S., Laudet, V., 2001. Euteleost fish genomes are characterized by expansion of gene families. Genome Res. 11, 781 788.

Rønnestad, I., Koven, W., Tandler, A., Harel, M., Fyhn, H.J., 1998. Utilisation of yolk fuels in developing eggs and larvae of European sea bass Dicentrarchus labrax. Aquaculture, 162, 157170.

Rose, T.M., Schultz, E.R., Henikoff, J.G., Pietrokovski, S., McCallum, C.M., Henikoff, S., 1998. Consensus-degenerate hybrid oligonucleotide primers for amplification of distantly-related sequences. Nuc. Ac. Res. 26, 1628-1635.

Saarela, J, Jung, G., Hermann, M., Nimpf, J., Schneider, W.J., 2008. The patatin-like lipase family in Gallus gallus. BMC Genomics 9, 281.

Sargent, J., McEnvoy, L., Estevez, A., Bell, G., Bell, M,. Henderson, J., Tocher, D., 1999. Lipid nutrition of marine fish during early development: current status and future directions. Aquaculture 179, 217-229.

Segner, H., Storch, V., Reinecke, M., Kloas, W., Hanke, W., 1994. The development of functional digestive and metabolic organs in turbot, Scophthalmus maximus. Mar. Biol. 119, 471-486.

Shields, R.J., Bell, J.G., Luizi, F.S., Gara, B., Bromage, N.R., Sargent, J.R., 1999. Natural copepods are superior to enriched Artemia nauplii as feed for halibut larvae (Hippoglossus hippoglossus) in terms of survival, pigmentation and retinal morphology: Relation to dietary essential fatty acids. J. Nutr. 129, 1186-1194.

Shinkuma, S., Akiyama, M., Inoue, A., Aoki, J., Natsuga, K., Nomura, T., Arita, K., Abe, R., Ito, K., Nakamura, H., Ujiie, H., Shibaki, A., Suga, H., Tsunemi, Y., Nishie, W., Shimizu, H., 2012. Prevalent LIPH founder mutations lead to loss of P2Y 5 activation ability of PA-PLA1alpha in autosomal recessive hypotrichosis. Hum. Mutat. 31, 602-610. 
Schrader, M., Bonekamp, N.A., Islinger, M., 2012. Fission and proliferation of peroxisomes. Biochim. Biophys. Acta 1822, 1343-1357.

Schoonjans, K., Peinado-Onsurbe, J., Lefebvre, A.-M., Heyman, R.A., Briggs, M., Deeb, S., Staels, B., Auwerx, J., 1996. PPAR $\alpha$ and PPAR $\gamma$ activators direct a distinct tissue-specific transcriptional response via a PPRE in the lipoprotein lipase gene. EMBO J. 15, 5336-5348.

Schupp, M., Lazar, M.A., 2010. Endogenous ligands for nuclear receptors: digging deeper. J. Biol. Chem. 285, 40409-40415.

Silversand, C., Norberg, B., Haux, C., 1996. Fatty-acid composition of ovulated eggs from wild and cultured turbot (Scophthalmus maximus) in relation to yolk and oil globule lipids. Mar. Biol. 125, 269-278.

Simopoulos, A.P., 2000. Human requirements for n-3 polyunsaturated fatty acids. Poult. Sci. 79, 961970.

Sprecher, H., 1992. A reevaluation of the pathway for the biosynthesis of 4,7,10,13,16,19docosahexaenoic acid. Omega-3 News 7, 1-3.

Stapleton, C.M., Mashek, D.G., Wang, S., Nagle, C.A., Cline, G.W., Thuillier, P., Leesnitzer, L.M., Li, L.O., Stimmel, J.B., Shulman, G.I., Coleman, R.A., 2011. Lysophosphatidic Acid Activates Peroxisome Proliferator Activated Receptor- $\gamma$ in CHO Cells That Over-Express Glycerol 3Phosphate Acyltransferase-1. PLoS One 6:e18932. doi:10.1371/journal.pone.0018932.

Tocher, D.R., 2003. Metabolism and functions of lipids and fatty acids in teleost fish. Rev. Fish. Sci. 11, 107-184.

Tocher, D.R., Agaba, M., Hastings, N., Teale, A.J., 2003. Biochemical and molecular studies of the polyunsaturated fatty acid desaturation in fish. The Big Fish Bang, Proceedings of the $26^{\text {th }}$ Annual Larval Fish Conference. (eds. Browman H.I.,Skiftesvik, A.B.), Bergen, Norway.

Tugwood, J.D., Holden, P.R., James, N.H., Prince, R.A., Roberts, R.A., 1998. A peroxisome proliferatoractivated receptor-alpha (PPARalpha) cDNA cloned from guinea-pig liver encodes a protein with similar properties to the mouse PPARalpha: implications for species differences in responses to peroxisome proliferators. Arch. Toxicol. 72, 169-177.

Varga, T., Czimmerer, Z., Nagy, L., 2011. PPARs are a unique set of fatty acid regulated transcription factors controlling both lipid metabolism and inflammation. Biochim. Biophys. Acta 1812, 10071022 .

Vandesompele, J., De Preter, K., Pattyn, F., Poppe, B., Van Roy, N., De Paepe, A., Speleman, F., 2002. Accurate normalization of real-time quantitative RT-PCR data by geometric averaging of multiple internal control genes. Gen. Biol. 3, 1-12.

Wang, Y.X., Lee, C.H., Tiep, S., Yu ,R.T., Ham, J., Kang, H., Evans, RM., 2003. Peroxisome proliferator-activated receptor activates fat metabolism to prevent obesity. Cell 13, 159-170.

Wiegand, M.D., 1996. Composition, accumulation and utilization of yolk lipids in teleost fish. Rev. Fish. Biol. Fish. 6, 259-286.

Xu, H.E., Lambert, M.H., Montana, V.G., Parks, D.J., Blanchard, S.G., Brown, P.J. Sternbach, D.D., Lehmann, J.M., Wisely, G.B., Willson, T.M., Kliewer, S.A., Milburn, M.V., 1999. Molecular recognition of fatty acids by peroxisome proliferator-activated receptors. Mol. Cell. 3, 397-403.

Yamamoto, Y., Kabeya, N., Takeuchi, Y., Alimudin Haga, Y., Satoh, S., Takeuchi, T., Yoshizaki, G., 2010. Cloning and nutritional regulation of polyunsaturated fatty acid desaturase and elongase of a marine teleost, the nibe croaker Nibea mitsukurii. Fish. Sci. 76, 463-472.

\section{Figure captions}


1 Fig. 1 - Photographs of turbot larva yolk-sac (YS) and oil globule (OG) along development. A at hatching (4.5 dpf); B - at mouth opening ( $7 \mathrm{dpf})$; $\mathrm{C}$ - at 50\% mortality ( $9 \mathrm{dpf})$. $\mathrm{H}$ - heart; IL intestinal loop; OT - otolith; PI - posterior intestine; S - stomach.

Fig. 2 - Schematic representation of the analyzed gene families, positioned at their respective cellular components and catalyzing a biochemical process on lipid metabolism.

Fig. 3 - Transcription level of genes involved in FA hydrolysis (Acot7, Acot8), FA activation (Acsl2,Acsl4) and $\beta$-oxidation (Acoxl and Cptla-rel), represented as mean values ( \pm standard error) along turbot larvae development, from notochord formation (NT) to 50\% mortality $(50 \% \mathrm{M}) . \mathrm{H}$ - hatching; $\mathrm{MO}$ - mouth opening. One-way ANOVA F-test statistic and test probability (p) are presented. Different letters ( $a, b, c)$ mean significant differences on expression levels between developmental stages after Tukey test $(\mathrm{p}<0.05)$.

Fig. 4 - Transcription level of genes involved in FA biosynthesis (Fasn) and desaturation (Fads2, Scd1 a and Scd1b) represented as mean values ( \pm standard error)along turbot larvae development, from notochord formation (NT) to $50 \%$ mortality $(50 \% \mathrm{M})$. H - hatching; $\mathrm{MO}-$ mouth opening. One-way ANOVA F-test statistic and test probability (p) are presented. Different letters $(a, b, c)$ mean significant differences on expression levels between developmental stages after Tukey test $(\mathrm{p}<0.05)$.

Fig. 5 - Transcription level for genes involved in FA elongation (Elovl1, Elovl4a, Elovl4b, Elovl5, Elovl6 and Elov6l) represented as mean values ( \pm standard error) along turbot larvae development, from notochord formation (NT) to $50 \%$ mortality $(50 \% \mathrm{M})$. H - hatching; $\mathrm{MO}-$ mouth opening. One-way ANOVA F-test statistic or one-way Kruskal-Wallis H-statistic and tests probability $(p)$ are presented. Different letters (a, b, c) mean significant differences on expression levels between developmental stages after Tukey or Dunn's test $(p<0.05)$.

Fig. 6 - Transcription level of genes involved in hydrolysis of TG and PL (LipA, LipE, LipH and Lpl) represented as mean values ( \pm standard error) along turbot larvae development, from notochord formation (NT) to $50 \%$ mortality $(50 \% \mathrm{M})$. $\mathrm{H}$ - hatching; $\mathrm{MO}$ - mouth opening. Oneway ANOVA F-test statistic or one-way Kruskal-Wallis H-statistic and tests probability (p) are presented. Different letters $(a, b, c)$ mean significant differences on expression levels between developmental stages after Tukey or Dunn's test $(\mathrm{p}<0.05)$. 
1 Fig. 7 - Transcription level of genes involved in FA esterification to TG and CE (Dgat1, Dgat2 and Soat2) represented as mean values ( \pm standard error) along turbot larvae development, from notochord formation (NT) to $50 \%$ mortality $(50 \% \mathrm{M})$. H - hatching; $\mathrm{MO}$ - mouth opening. Oneway ANOVA F-test statistic and test probability (p) are presented. Different letters (a, b, c, d) mean significant differences on expression levels between developmental stages after Tukey test $(\mathrm{p}<0.05)$.

Fig. 8 - Transcription level of genes involved in FA metabolism control (PPAR $\alpha 1, P P A R \alpha 2$, $P P A R \beta$ and $P P A R \gamma$ ) represented as mean values ( \pm standard error) along turbot larvae development, from notochord formation (NT) to $50 \%$ mortality $(50 \% \mathrm{M}) . \mathrm{H}$ - hatching; $\mathrm{MO}-$ mouth opening. One-way ANOVA F-test statistic or one-way Kruskal-Wallis H-statistic and tests probability $(p)$ are presented. Different letters (a, b, c, d) mean significant differences on expression levels between developmental stages after Tukey or Dunn's test $(p<0.05)$.

Fig. 9 - Principal Component (PC) plot representing variables in the rotated plan after Principal Component Analysis. Rotation method was Varimax with Kaiser Normalization. Near each PC it is presented the percentage of data variation explained by it. G1, G2 and G3 correspond to the 3 variables' groups defined.

Fig. 10 - Circos diagram showing correlations between each PPAR and the various target genes. The degree of correlation is set by the ribbon color in 4 levels corresponding to 4 quartiles, from the lowest to the highest correlated: Q1 - quartile ribbons have color grey, Q2 - quartile ribbons have color yellow, Q3 - quartile ribbons have color orange, Q4 - quartile ribbons have color red. Only significant correlations $($ level $<0.05)$ are presented. Segments on the extreme of the ribbons represent the color in the opposite side. Cpt1a-rel and Dgat2 are not presented since they are not significantly correlated to any PPAR.

Fig. 11 - Schematic description of the morphological, biochemical and molecular events along larval development from notochord formation in the egg to $50 \%$ mortality in starving (non feed) larvae at 3 days after mouth opening. 


\section{$1 \quad$ Table 1}

2 Yolk sac volume, oil globule volume and total lipid content along early development of turbot

3 (dpf - days post fertilization). Values correspond to the mean \pm standard deviation of $15-20$

4 larvae for yolk sac and oil globule volume and, of 2 pooled samples $(n=175-400$ eggs or

5 larvae) for total lipids and total fatty acids. Different superscript letter in the same row indicate

$6 \quad$ significant differences $(\mathrm{p}<0.05)$.

7

\begin{tabular}{lcccc}
\hline Days Post Fertilization (dpf) & 2.5 & 4.5 & 7 & 9 \\
\hline $\begin{array}{l}\text { Developmental event } \\
\text { Yolk sac }(\mu \mathrm{l})\end{array}$ & $\begin{array}{c}\text { notochord } \\
\text { formation }\end{array}$ & hatching & mouth opening & $50 \%$ mortality 9 \\
Oil Globule $(\mathrm{nl})$ & - & $0.278 \pm 0.020^{\mathrm{a}}$ & $0.022 \pm 0.002^{\mathrm{b}}$ & - \\
Total Lipids $(\mu \mathrm{g} / \mathrm{egg}$ or larva) & $9.63 \pm 0.28^{\mathrm{a}}$ & $9.98 \pm 0.37^{\mathrm{a}}$ & $6.90 \pm 0.23^{\mathrm{b}}$ & $3.92 \pm 0.03^{\mathrm{c}}$ \\
Total Fatty Acids $(\mu \mathrm{g} / \mathrm{egg}$ or larva) & $5.30 \pm 0.22^{\mathrm{a}}$ & $5.25 \pm 0.04^{\mathrm{a}}$ & $3.76 \pm 0.19^{\mathrm{ab}}$ & $1.62 \pm 0.15^{\mathrm{b}}$ \\
\hline
\end{tabular}




\section{$1 \quad$ Table 2}

2 Triglycerides, phospholipids, sterols, Sterols esters + Wax esters and free fatty acids content

3 ( $\mu \mathrm{g} /$ larvae or egg) along early development of turbot ( $\mathrm{dpf}-$ days post fertilization). Values

4 correspond to the mean \pm standard deviation of 2 pooled samples ( $n=175-400$ eggs or larvae)

5 for lipid classes analysis. Different superscript letter in the same row indicate significant

6 differences $(\mathrm{p}<0.05)$.

7

\begin{tabular}{|c|c|c|c|c|}
\hline Days Post Fertilization (dpf) & 2.5 & 4.5 & 7 & 9 \\
\hline Developmental event & $\begin{array}{l}\text { notochord } \\
\text { formation }\end{array}$ & hatching & mouth opening & $50 \%$ mortality $_{9}$ \\
\hline Triglycerides (TG) & $1.20 \pm 0.05^{\mathrm{a}}$ & $1.23 \pm 0.04^{\mathrm{a}}$ & $0.62 \pm 0.09^{b}$ & - \\
\hline Phospholipids (PL) & $1.65 \pm 0.02^{\mathrm{a}}$ & $1.75 \pm 0.07^{\mathrm{ab}}$ & $2.08 \pm 0.11^{\mathrm{b}}$ & $1.47 \pm 0.18^{10}$ \\
\hline Sterols (SL) & $0.40 \pm 0.01^{\mathrm{a}}$ & $0.35 \pm 0.01^{\mathrm{a}}$ & $0.54 \pm 0.05^{\mathrm{b}}$ & $0.51 \pm 0.02^{b}$ \\
\hline $\begin{array}{l}\text { Sterols Esters + Waxes Esters } \\
(\mathrm{SE}+\mathrm{W})\end{array}$ & $1.11 \pm 0.01^{\mathrm{a}}$ & $1.15 \pm 0.09^{\mathrm{a}}$ & $0.40 \pm 0.05^{\mathrm{b}}$ & $0.07 \pm 0.01^{\mathrm{c}}$ \\
\hline Free Fatty Acids (FFA) & - & - & $0.03 \pm 0.02$ & $0.01 \pm 0.02$ \\
\hline
\end{tabular}




\section{$1 \quad$ Table 3}

2 Saturated, monounsaturated, polyunsaturated, n-3 series and n-6 series fatty acids content

3 ( $\mu \mathrm{g} /$ larvae or egg) along early development of turbot ( $\mathrm{dpf}-$ days post fertilization). Values

4 correspond to the mean \pm standard deviation of 2 pooled samples $(n=175-400$ eggs or larvae)

5 for fatty acids analysis. Different superscript letter in the same row indicate significant

6 differences $(\mathrm{p}<0.05)$.

7

\begin{tabular}{lcccc}
\hline Days Post Fertilization (dpf) & 2.5 & 4.5 & 7 & 9 \\
\hline Developmental event & $\begin{array}{l}\text { notochord } \\
\text { formation }\end{array}$ & hatching & mouth opening & $50 \%$ mortality \\
\hline Saturated Fatty Acids & $1.80 \pm 0.07^{\mathrm{a}}$ & $1.83 \pm 0.03^{\mathrm{a}}$ & $1.47 \pm 0.09^{\mathrm{a}}$ & $0.75 \pm 0.09^{\mathrm{b}}$ \\
Monounsaturated Fatty Acids & $1.55 \pm 0.06^{\mathrm{a}}$ & $1.49 \pm 0.02^{\mathrm{a}}$ & $0.90 \pm 0.07^{\mathrm{b}}$ & $0.28 \pm 0.03^{\mathrm{c}}$ \\
Polyunsaturated Fatty Acids & $1.98 \pm 0.09^{\mathrm{a}}$ & $2.11 \pm 0.01^{\mathrm{a}}$ & $1.43 \pm 0.05^{\mathrm{b}}$ & $0.59 \pm 0.07^{\mathrm{c}}$ \\
n-3 series Fatty Acids & $1.76 \pm 0.01^{\mathrm{a}}$ & $1.85 \pm 0.03^{\mathrm{a}}$ & $1.29 \pm 0.07^{\mathrm{b}}$ & $0.51 \pm 0.02^{\mathrm{c}}$ \\
$\mathrm{n}-6$ series Fatty Acids & $0.22 \pm 0.00^{\mathrm{a}}$ & $0.25 \pm 0.01^{\mathrm{a}}$ & $0.15 \pm 0.02^{\mathrm{b}}$ & $0.07 \pm 0.01^{\mathrm{c}}$ \\
\hline
\end{tabular}




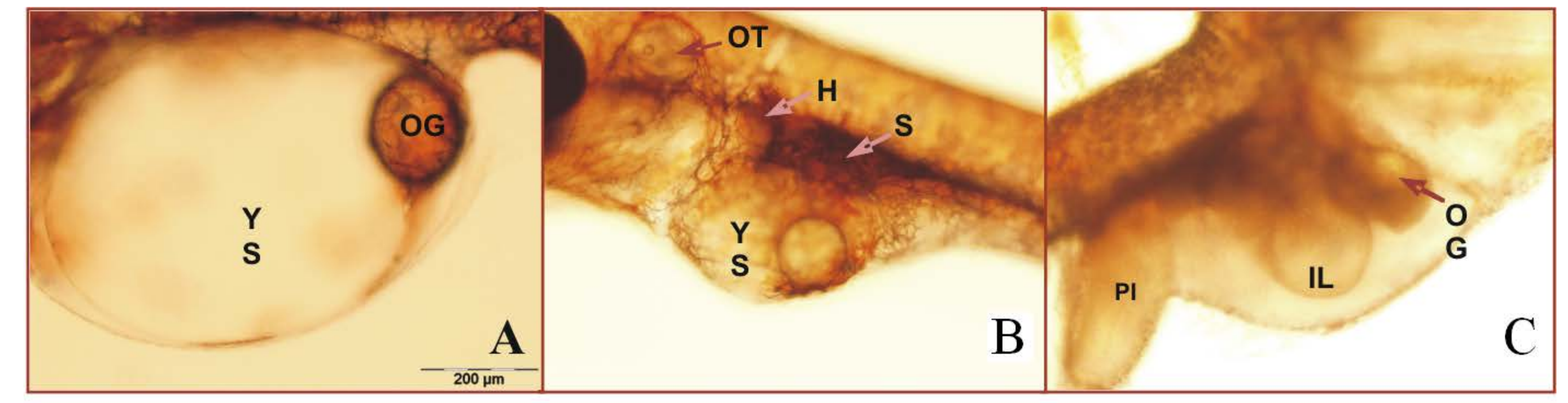

Fig. 1 


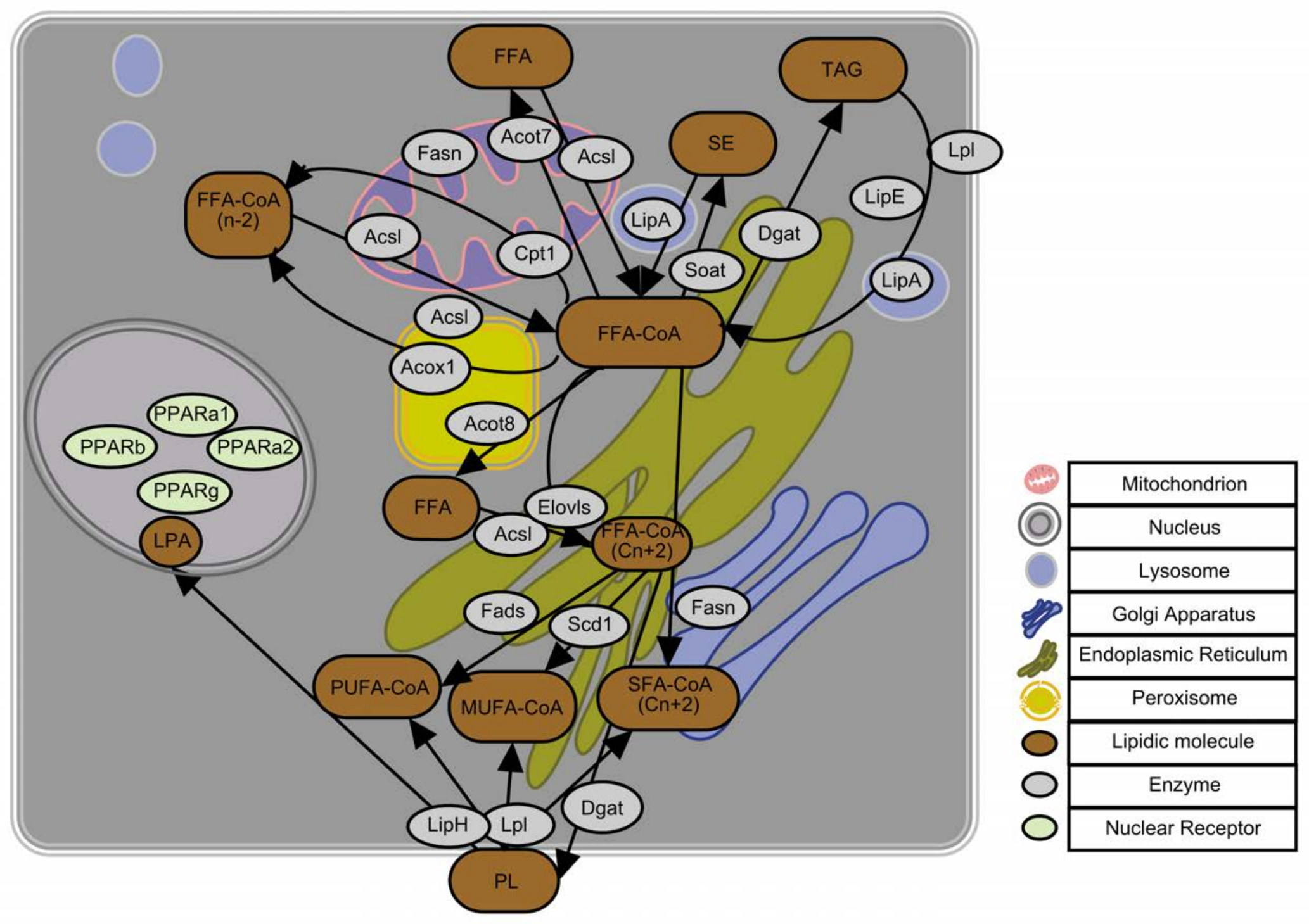

Fig.2 

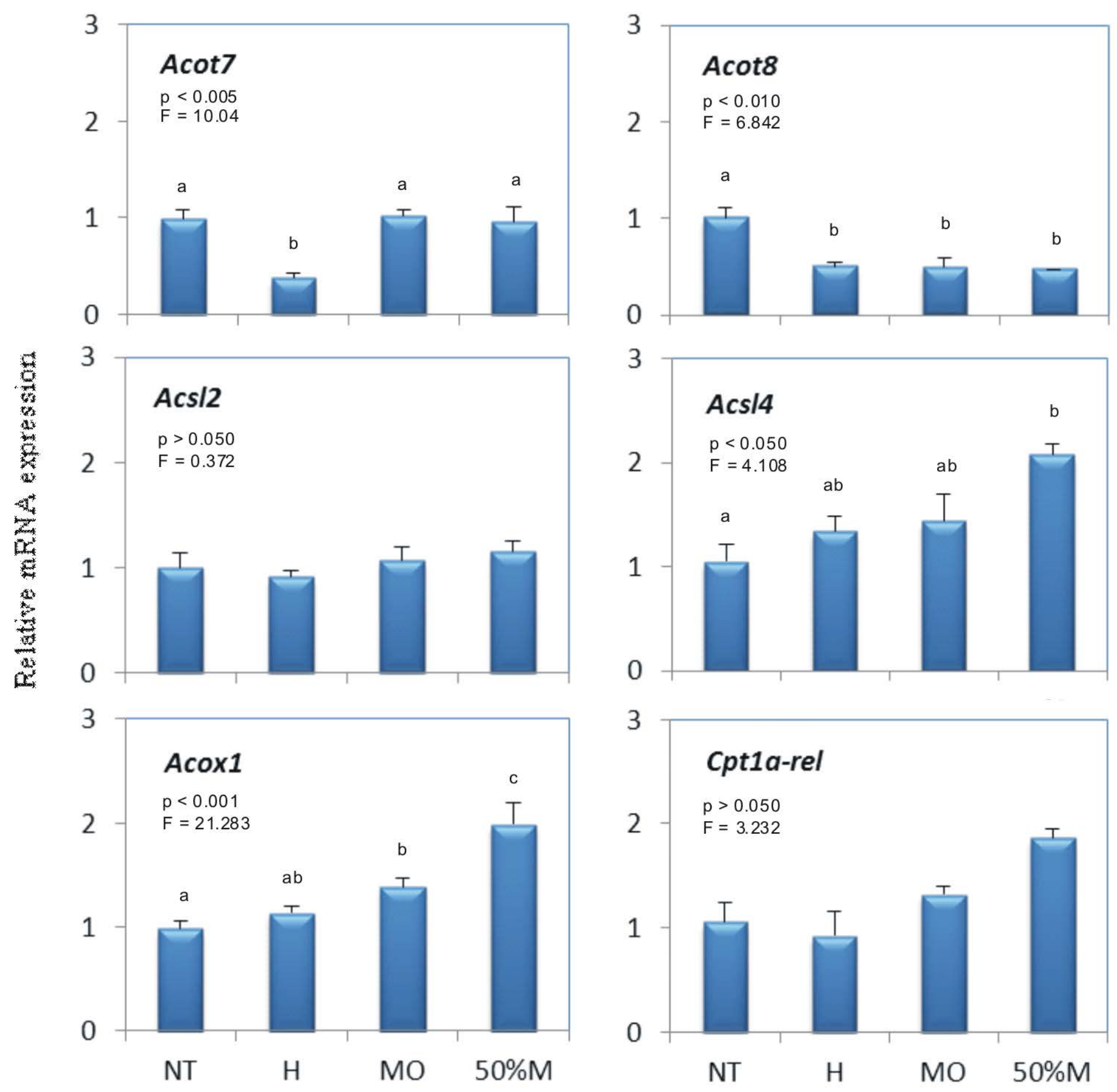

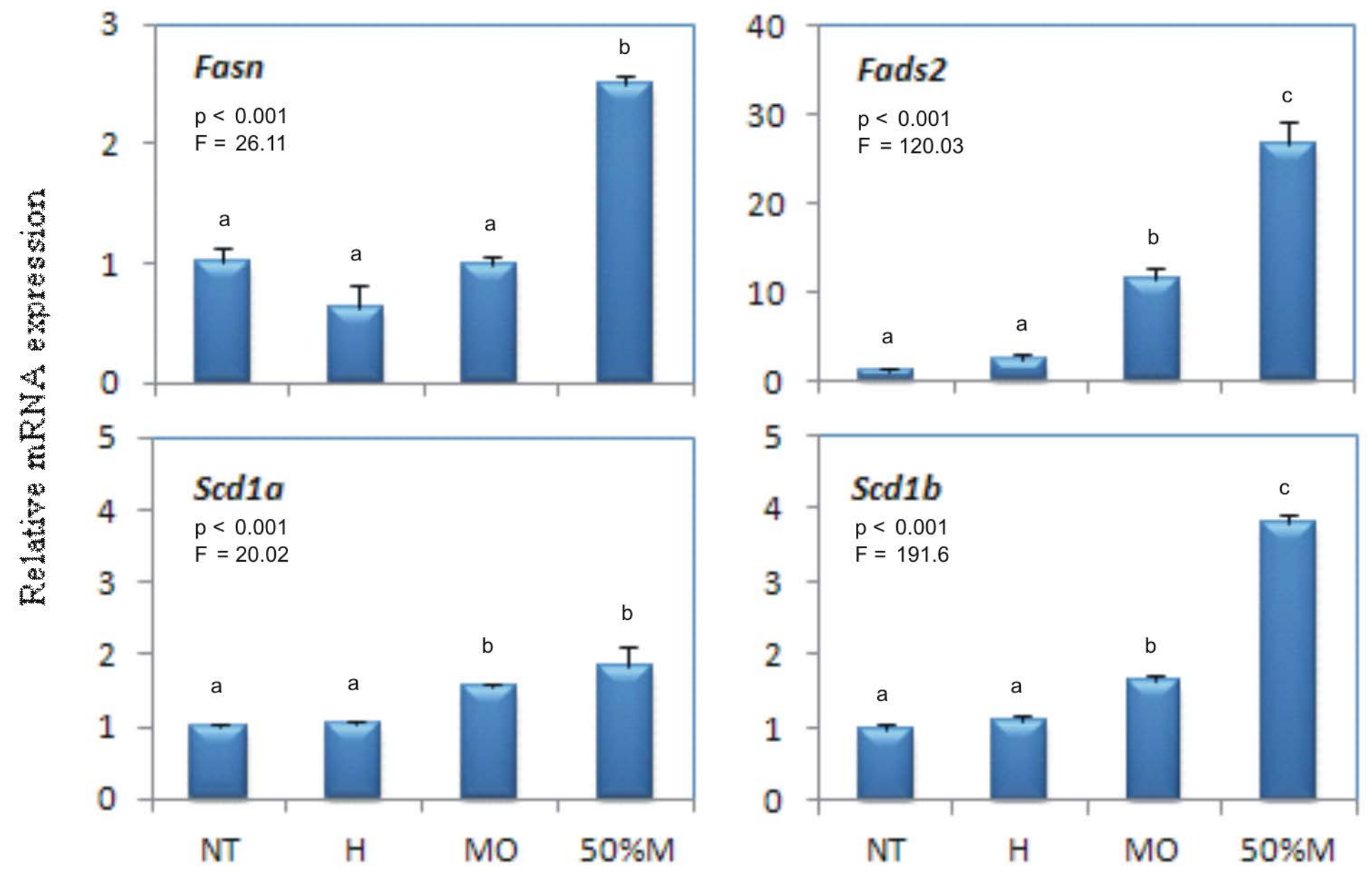

Fig.4 

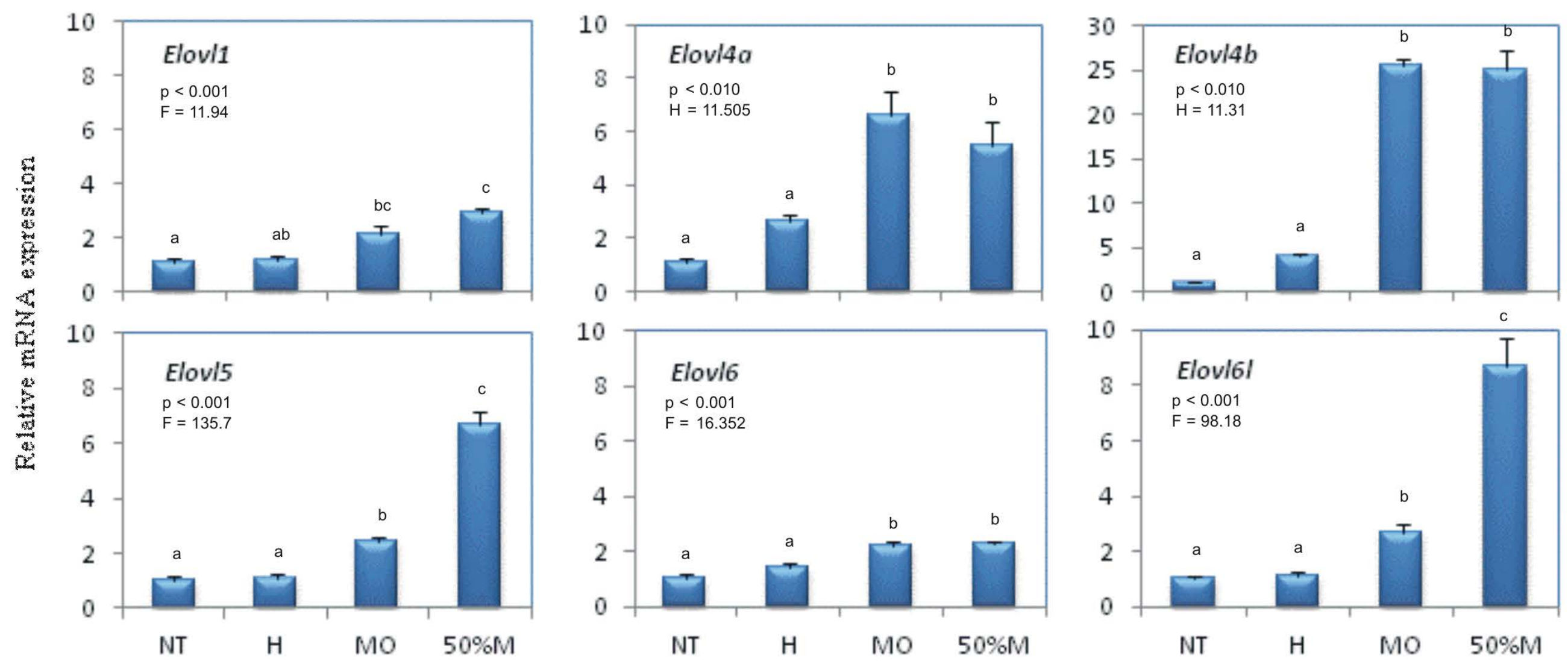

Fig.5 

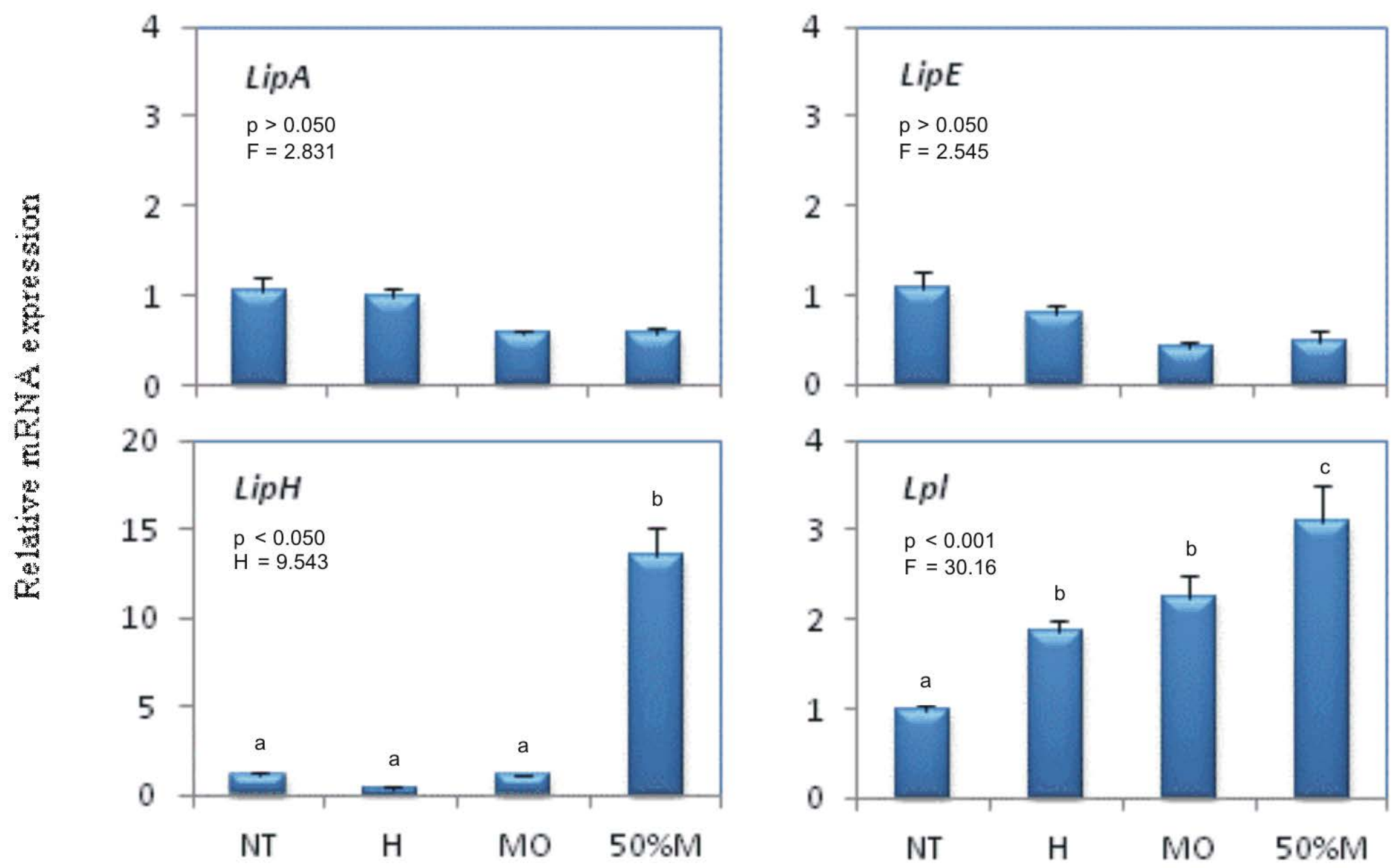

Fig.6 


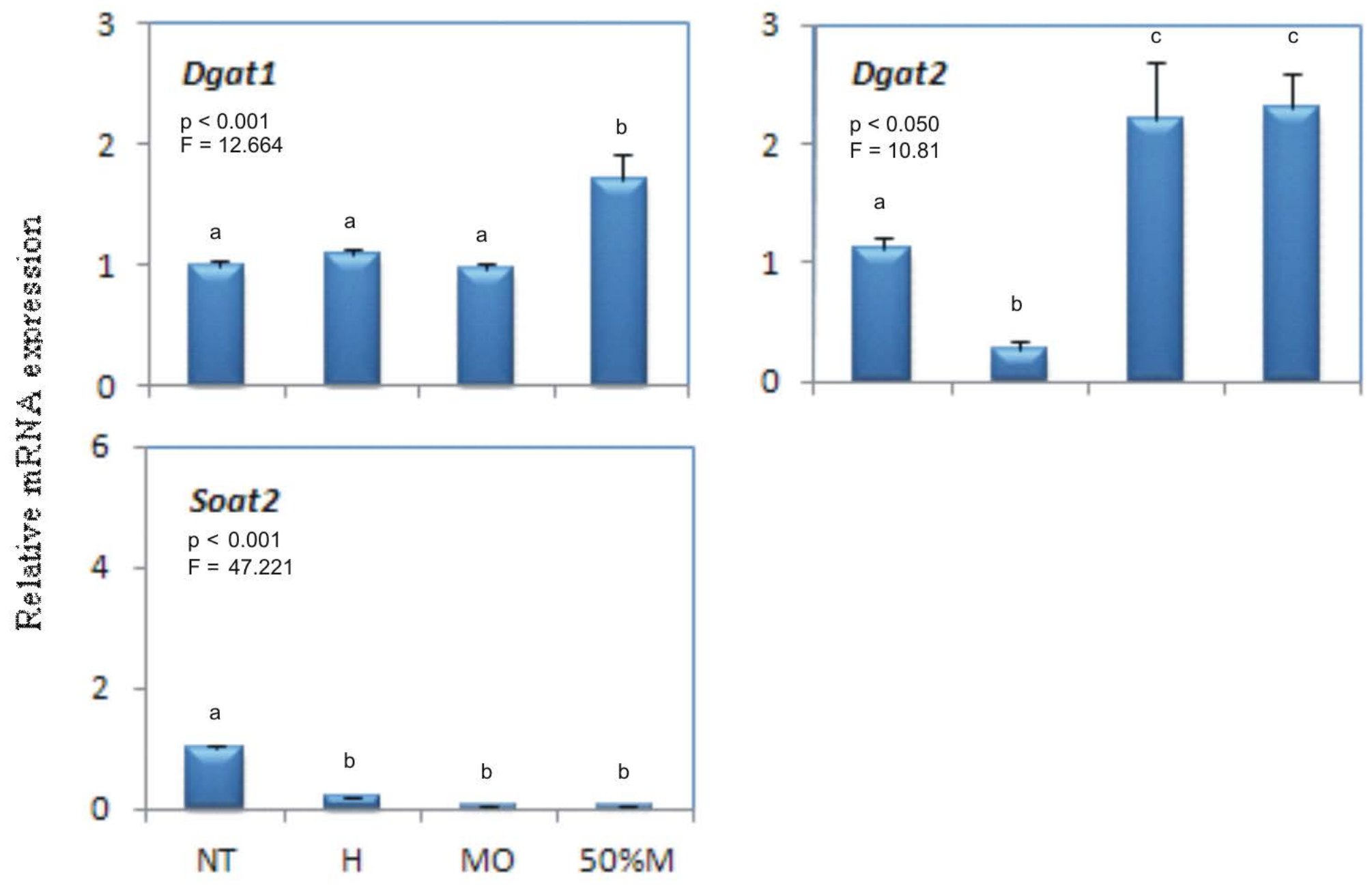

Fig. 7 

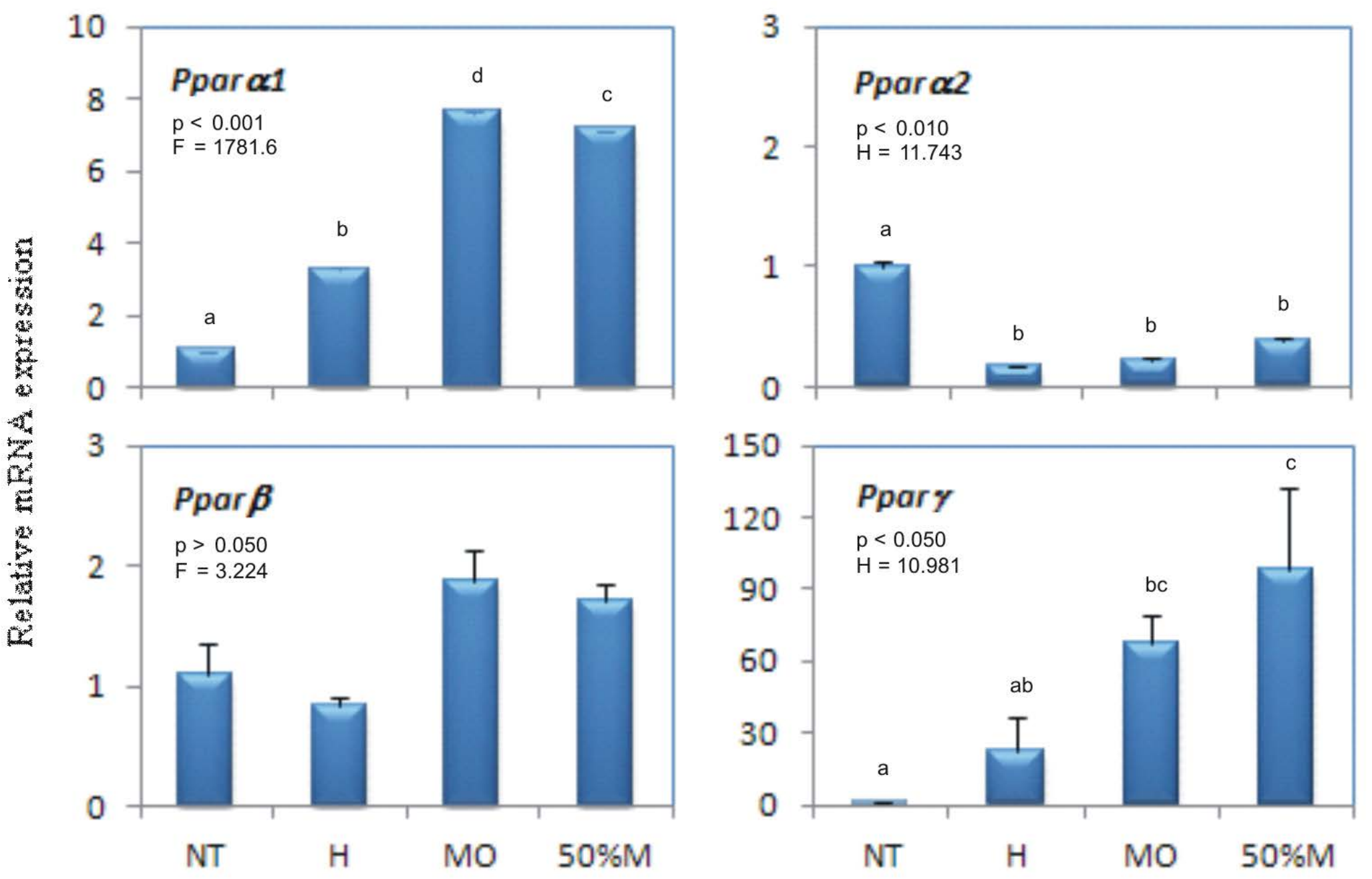

Fig.8 


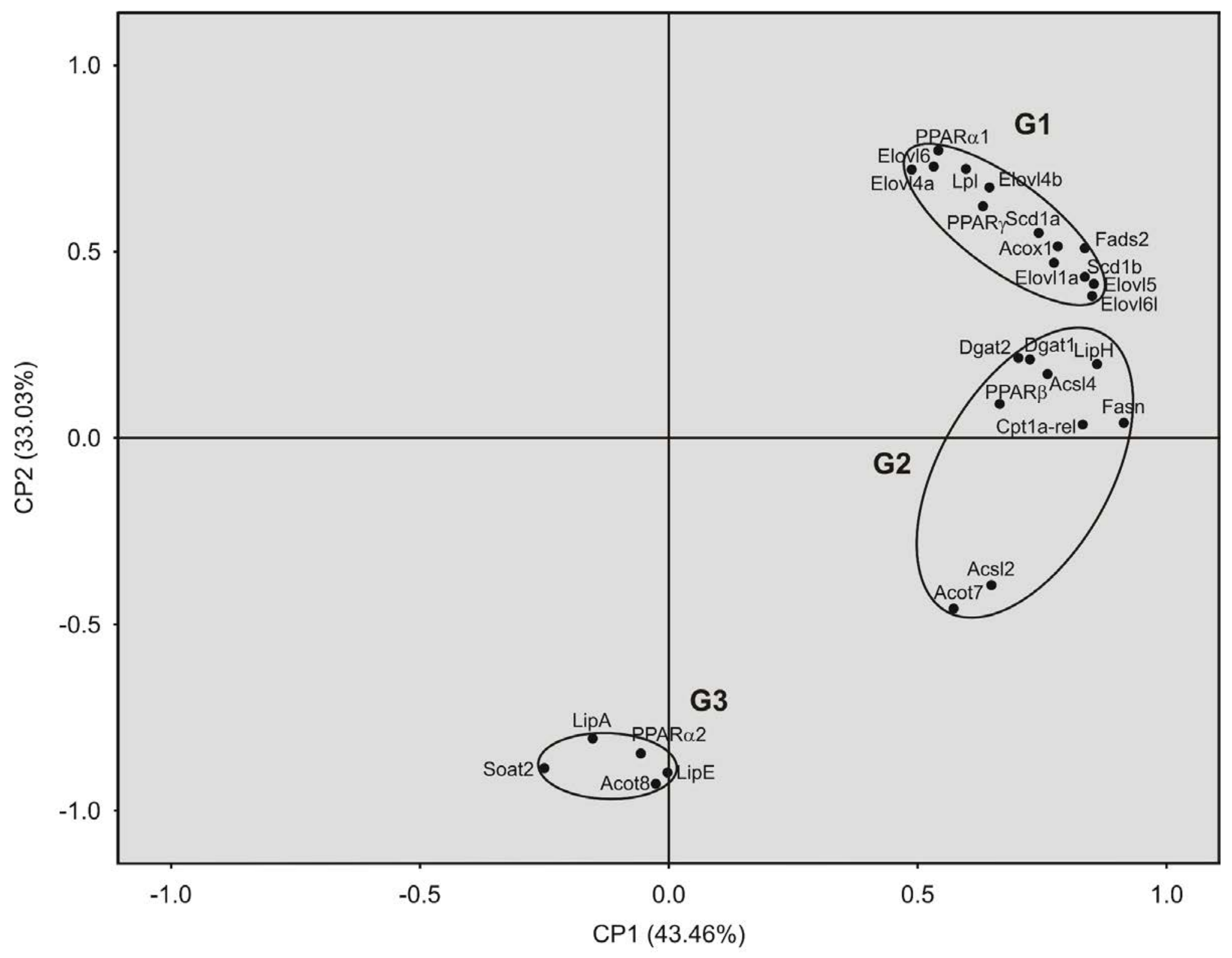

Fig. 9 


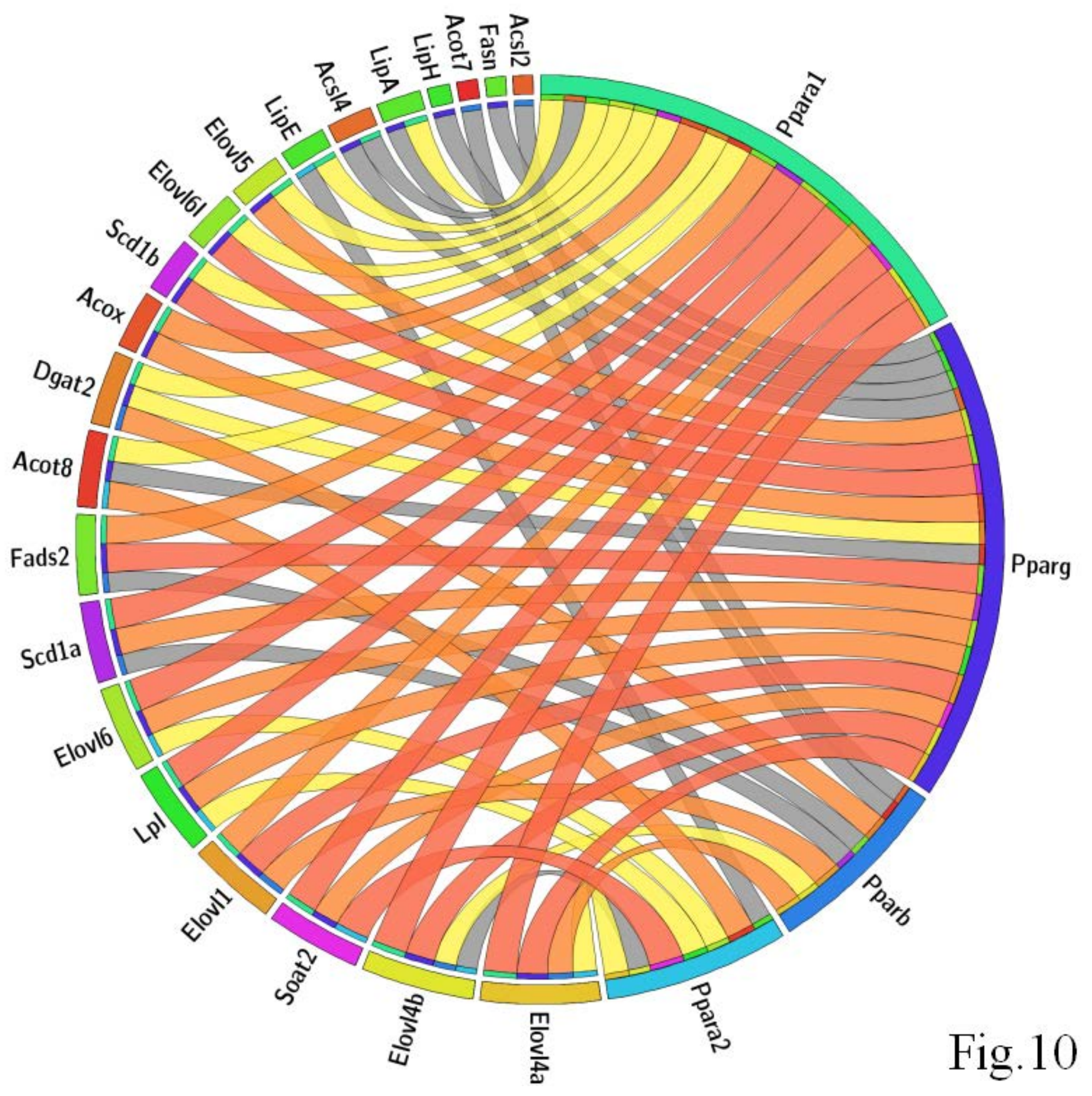




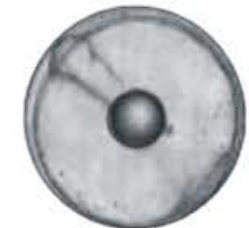

\section{5 days}

Notochord formation

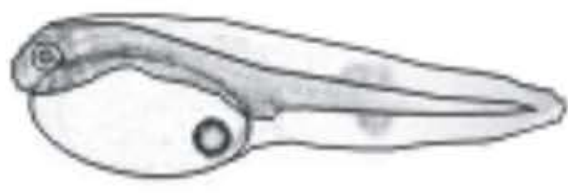

4.5 days

Hatching

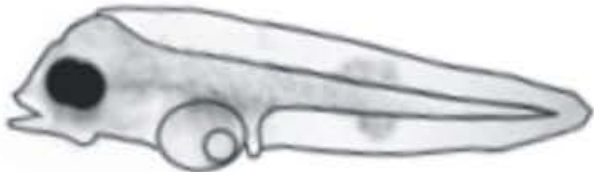

7 days

Mouth

Opening

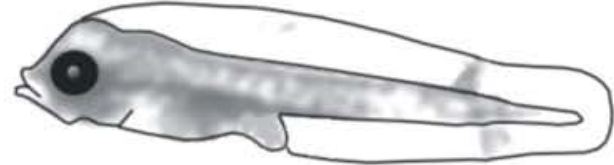

9 days

$50 \%$ Mortality

I I

EMBRYOS

ELEUTHEROEMBRYOS

LARVAE

- Oil globule volume constant;

- Lipid content does not change;

- TG, PL, SL and SE+WE levels do not

change;

- First transcriptional changes for genes involved in hydrolysis of TG and PL, and FA esterification

- Upregulation of PPAR $\alpha 1, L p l$ and Soat1;

- Downregulation of PPAR $\alpha 2$, Acots, Dgat2 and Soat2.

\section{Fig. 11}


Supplementary material 1. Details on the primer pairs used for real-time PCR amplification of the target and 5 reference genes, including nucleotide sequence of the sense and antisense (reversed) primers, amplicon size, amplification efficiency (E), coefficient of determination $\left(\mathrm{R}^{2}\right)$ of the primers' efficiency and NCBI accession number.

\begin{tabular}{|c|c|c|c|c|c|c|}
\hline $\begin{array}{l}\begin{array}{l}\text { Gene } \\
\text { symbol }\end{array} \\
\text { a }\end{array}$ & Sense primer & Reversed antisense primer & $\begin{array}{c}\text { Amplicon } \\
\text { Size }\end{array}$ & E (\%) & $\mathbf{R}^{2}$ & Accession Number \\
\hline \multicolumn{7}{|c|}{ Hydrolysis of $F A-C o A$ to $F A+C o A$} \\
\hline$A \cot 7$ & CTGGTTCGGGTGGAGAAG & GCTGCCTTGTTGGTCATC & 167 & 108.7 & 0.995 & KC189922 \\
\hline Acot 8 & GCCCACTTCCTCGCATCTC & GCACTCGTACAGCATCCATTC & 81 & 108.8 & 0.995 & KC461231 \\
\hline \multicolumn{7}{|c|}{ FA activation to $F A-C o A$} \\
\hline Acsl4 & AGTTCGGCAGTGGATTGG & CAGCGTGGCATAGAATGTC & 143 & 104.2 & 0.988 & KC189924 \\
\hline Acsl2 & CGGGCTGCTGGCTAAAGG & CTGAGATGATCCACTCTGGTCTG & 85 & 102.1 & 0.984 & KC189923 \\
\hline \multicolumn{7}{|c|}{ FA $\beta$-Oxidation } \\
\hline Cptla-rel & ATGGGAAGAGTGGACTGAATG & GCTGGAAGGCATCTGTGG & 96 & 105.7 & 0.996 & KC189926 \\
\hline Acoxl & CGACCAGGAGAGCCAGAG & AGCCATAGCCAGCAGAGG & 78 & 107.2 & 0.980 & KC189925 \\
\hline \multicolumn{7}{|c|}{ FA biosynthesis up to 16:0 } \\
\hline Fasn & AGTGGTAGTGCTGCTGAC & CTATGTTTGCCTCCTGGTAG & 164 & 89.3 & 0.993 & KC189927 \\
\hline \multicolumn{7}{|c|}{ FA desaturation } \\
\hline Scdla & CGTCCGAGGCTTCTTCTTC & CAGACAGCAGGTCGTTGAG & 104 & 102.9 & 0.989 & KC189928 \\
\hline Scdlb & TGGAGATGTTGGACCTGAAG & TTGAGCACCAGAGCGTATC & 178 & 94.1 & 0.990 & KC189929 \\
\hline Fads2 & TGTCCTACTATCTTCGCTTCTTC & TAACCAGTCCTTGTGCTTCTC & 170 & 116.7 & 0,973 & AY546094 \\
\hline \multicolumn{7}{|c|}{ FA incorporation into triglycerides } \\
\hline Elovlla & GGAAGCCTGATAGTCTACAAC & AATAATCTTTGAGAACCAGAACAG & 183 & 88.0 & 0.991 & KC189930 \\
\hline Elovl $4 a$ & TGTTCACGCTCTGGTGGATC & GCCGTAATACAGATACATCAGGAC & 107 & 87.8 & 0.968 & KC189931 \\
\hline Elovl $4 b$ & CTGGTGGATTGGCATCAAG & CGTGGAACTGGATCATCTG & 179 & 105.8 & 0.963 & KC189932 \\
\hline Elovl5 & AACTGAACACTTACATAGACTC & GATTGTAGACCACCAGGAG & 189 & 106.5 & 0.978 & AF465520 \\
\hline Elovl6 & CATCACCGTGCTGCTGTAC & GCCCGTAATGCGTAGTAAGAG & 120 & 113.3 & 0.994 & KC189933 \\
\hline Elovl6l & GTACCACTGGATGCACGAG & GCGAACAGCACCAGGTAG & 93 & 91.8 & 0.982 & KC461232 \\
\hline \multicolumn{7}{|c|}{ FA incorporation into triglycerides } \\
\hline Dgatl & ATACTCGTGTCCATCTGTGTCTC & AGTCGTCTCATCAGGAACCTTAC & 177 & 101.9 & 0.993 & KC189938 \\
\hline Dgat2 & TGCTGTGGTCATCGTTATC & CTTGTAGGCGTCGTTCTC & 163 & 105.3 & 0.981 & KC189939 \\
\hline \multicolumn{7}{|c|}{ FA incorporation into cholesteryl esters } \\
\hline Soat 2 & GCTCGTGATGTTCGTCTAC & TGAATGGAGGACAAGATTAACC & 129 & 84.4 & 0.993 & KC189940 \\
\hline \multicolumn{7}{|c|}{ Hydrolysis of triglycerides and phospholipids } \\
\hline LipA & ACGATAGCATTCATAGCATTCTC & GGCAGGACGGACATCTTG & 128 & 95.1 & 0.991 & KC189934 \\
\hline LipE & CATAACAGGCTTGAACAG & GCTCGTAGGAGATTAGAC & 179 & 98,6 & 0,993 & KC189935 \\
\hline LipH & GGCAGGTCCGATGTTCAC & GCTCCTCTCAGTCCGAATG & 111 & 76.9 & 0.998 & KC189936 \\
\hline Lpl & CGCTCTATCCACCTGTTC & GGACCTTGTTGATGTTGTAG & 154 & 109.1 & 0.987 & KC189937 \\
\hline \multicolumn{7}{|c|}{ Nuclear receptors involved in FA metabolism } \\
\hline PPAR $\alpha 1$ & GCGTCCCTTCAGTGATAT & CTCCACAGCAGATGATAG & 137 & 97.5 & 0.967 & JX975469 \\
\hline PPAR $\alpha 2$ & AAGTTCCAGTTCGCCACAC & GGTCTCCGCAGCAGATTATG & 90 & 108,7 & 0.976 & JX975470 \\
\hline$P P A R b$ & ACAAGTCAACACAGCCTAC & CGCACCTGGAAGTAACTG & 166 & 98.7 & 0.990 & KC189941 \\
\hline PPARg & TAATGGAAGGAGAGCAGTTC & CTGTGGAAGAAGCGTAGC & 193 & 130.9 & 0.970 & KC189932 \\
\hline \multicolumn{7}{|c|}{$\underline{\text { Reference Genes }}$} \\
\hline$b$-Actin & TGGCATCATACCTTCTACAATG & TACGACCAGAGGCATACAG & 187 & 99.4 & 0.999 & EU686692 \\
\hline$E F-1 a$ & TATTAACATCGTGGTCATTGG & CAGGCGTACTTGAAGGAG & 153 & 90.3 & 0.991 & AF467776 \\
\hline RPL8 & CTCCGCCACATTGACTTC & GCCTTCTTGCCACAGTAG & 197 & 101.2 & 0.986 & DQ848874 \\
\hline$U B 2 L 3$ & GGTCTGCCTGCCTATCATC & TGTATTCTTCTGCCAGGTCTG & 137 & 102.5 & 0.985 & KC355244 \\
\hline $18 S$ & CCAACACGGGAAACCTCAC & ATCGCTCCACCAACTAAGAAC & 111 & 105.8 & 0.990 & EF126038 \\
\hline
\end{tabular}


Supplementary material 2. Rotated Matrix with variables' factor loadings. Extraction method was Principal Component Analysis. Rotation method was Varimax with Kaiser Normalization. Rotation converged in 3 iterations. Red italic marked loadings are greater than 0.8 .

\begin{tabular}{lcc}
\hline & $\mathrm{CP} 1$ & $\mathrm{CP} 2$ \\
\hline Acot7 & 0.572 & -0.457 \\
Acot8 & -0.026 & -0.927 \\
Acox1 & 0.782 & 0.515 \\
Acsl4 & 0.761 & 0.172 \\
Acsl2 & 0.648 & -0.394 \\
Cpt1a-rel & 0.831 & 0.037 \\
Dgat1 & 0.702 & 0.216 \\
Dgat2 & 0.725 & 0.212 \\
Elovl1 & 0.773 & 0.471 \\
Elovl4a & 0.488 & 0.721 \\
Elovl4b & 0.644 & 0.673 \\
Elovl5 & 0.854 & 0.414 \\
Elovl6 & 0.532 & 0.729 \\
Elovl6l & 0.850 & 0.381 \\
Fads2 & 0.836 & 0.510 \\
Fasn & 0.914 & 0.042 \\
LipA & -0.153 & -0.806 \\
LipE & 0.003 & -0.898 \\
LipH & 0.860 & 0.199 \\
Lpl & 0.597 & 0.723 \\
Scdla & 0.743 & 0.551 \\
Scdlb & 0.836 & 0.433 \\
Soat2 & -0.251 & -0.885 \\
PPAR $\alpha 1$ & 0.541 & 0.773 \\
PPAR $\alpha 2$ & -0.056 & -0.846 \\
PPAR $\beta$ & 0.665 & 0.092 \\
PPAR & 0.631 & 0.623 \\
\hline & & \\
\hline
\end{tabular}


Supplementary material 3. Correlation coefficient of the relationship between the transcription rate of each PPAR and the various target genes analyzed $(\mathrm{N}=28)$. Red bold marked correlation factors are significant at 0.01 level and blue italic marked ones are significant at 0.05 level.

\begin{tabular}{|c|c|c|c|c|}
\hline & $P P A R \alpha 1$ & $P P A R \alpha 2$ & $P P A R \beta$ & $P P A R \gamma$ \\
\hline$A \cot 7$ & 0.082 & 0.468 & 0.564 & 0.042 \\
\hline Acot 8 & -0.706 & 0.787 & 0.100 & -0.565 \\
\hline Acoxl & 0.767 & -0.432 & 0.452 & 0.784 \\
\hline Acsl4 & 0.601 & -0.432 & 0.449 & 0.609 \\
\hline Acsl2 & 0.204 & 0.065 & 0.540 & 0.244 \\
\hline Cptla-rel & 0.493 & -0.180 & 0.455 & 0.498 \\
\hline Dgat1 & 0.392 & -0.180 & 0.124 & 0.425 \\
\hline Dgat2 & 0.664 & -0.132 & 0.712 & 0.622 \\
\hline Elovl1 & 0.790 & -0.399 & 0.768 & 0.833 \\
\hline Elovl4a & 0.941 & -0.683 & 0.721 & 0.860 \\
\hline Elovl4b & 0.974 & -0.609 & 0.626 & 0.825 \\
\hline Elovl5 & 0.688 & -0.337 & 0.425 & 0.746 \\
\hline Elovl6 & 0.911 & -0.654 & 0.396 & 0.742 \\
\hline Elovl6l & 0.658 & -0.318 & 0.497 & 0.816 \\
\hline Fads2 & 0.797 & -0.436 & 0.556 & 0.815 \\
\hline Fasn & 0.416 & -0.004 & 0.384 & 0.550 \\
\hline LipA & -0.667 & 0.477 & -0.227 & -0.535 \\
\hline LipE & -0.659 & 0.571 & -0.035 & -0.505 \\
\hline LipH & 0.474 & -0.152 & 0.347 & 0.601 \\
\hline$L p l$ & 0.857 & -0.700 & 0.441 & 0.813 \\
\hline Scdla & 0.862 & -0.444 & 0.571 & 0.741 \\
\hline$S c d 1 b$ & 0.685 & -0.341 & 0.440 & 0.818 \\
\hline Soat2 & -0.867 & 0.955 & -0.272 & -0.730 \\
\hline PPAR $\alpha 1$ & & -0.749 & 0.588 & 0.847 \\
\hline$P P A R \alpha 2$ & & & -0.180 & -0.583 \\
\hline$P P A R \beta$ & & & & 0.586 \\
\hline
\end{tabular}

